\title{
ISSI2020:An Approach for Obtaining Material Mechanical Properties in Structure Local Region Based on An Accurate Analysis of Micro- Indentation Test
}

HeXue ( $\nabla$ xuehe@xust.edu.cn)

Xi'an University of Science and Technology https://orcid.org/0000-0003-0315-9386

Jinxuan He

Xi'an University of Science and Technology

Jianlong Zhang

Xi'an Special Equipment Inspection Institute

Yuxuan Xue

University of Hong Kong

\section{Original Article}

Keywords: Structural integrity assessment, Micro-indentation test, Numerical testing inversion analysis, Local material mechanical property

Posted Date: January 6th, 2021

DOI: https://doi.org/10.21203/rs.3.rs-139254/v1

License: (c) (i) This work is licensed under a Creative Commons Attribution 4.0 International License.

Read Full License 


\section{Title page}

\section{An Approach for Obtaining Material Mechanical Properties in Structure Local Region Based on An Accurate Analysis of Micro-indentation Test}

He Xue, born in 1961, is currently a professor at Xi'an University of Science and Technology, China. He received his PhD degree in 1998 from Xi'an Jiaotong University, China. His research interests is safety evaluation of important mechanical structures.

Tel: +86-13088958007; E-mail: xuehe@xust.edu.cn

Jin-Xuan He, born in 1994, is currently a master candidate at School of Mechanical Engineering, Xi'an University of Science and Technology, China. His research interests is safety evaluation of important mechanical structures.

Tel: +86-13572579708; E-mail: 84118631@qq.com

Jian-long Zhang, born in 1988, is currently an engineer at Xi'an Special Equipment Inspection Institute, China. He received his PhD degree in 2020 from Xi'an University of Science and Technology, China.

Tel: +86-13679269699; E-mail: 527449153@qq.com

Yu-xuan Xue, born in 1994, is currently a Phd candidate at Department of Industrial and Manufacturing Systems Engineering, The University of HongKong, China. His research interests is nanorobotics and micro-mechanics.

Tel: +852-68132457; E-mail: xueyuxuan@hku.hk

\section{Corresponding author: He Xue E-mail: xuehe@xust.edu.cn}




\title{
An Approach for Obtaining Material Mechanical Properties in Structure Local Region Based on An Accurate Analysis of Micro-indentation Test
}

\author{
He Xue $^{1} \bullet$ Jin-Xuan He ${ }^{1} \cdot$ Jian-long Zhang² $\bullet$ Yu-Xuan Xue
}

\begin{abstract}
The welding and other hot or cold processing region behavior in important structures is the key characteristics for the structural integrity assessment, it is necessary to accurately derive the material mechanical properties in the failure driving force (such as stress and strain) analysis in the local area. The hot or cold processing would induce the change and the inhomogeneous of the material mechanical properties in the local processing region of the structure, and it is difficult to obtain the precise mechanical properties in these regions by the traditional material tensile test.

To accurately obtain actual material mechanical properties in the local region of structures, a micro-indentation test system has been established, which incorporated by a CMT6103 Material Test Device, an indenter displacement sensor and a group of special micro-indenter assemblies are established, and a numerical testing inversion analysis method by using ABAQUS software is also proposed in this paper. Based on above test system and analysis platform, an approach to obtain material mechanical properties in local region of structure is proposed and established. The verification experiment and analysis is performed by using a group of various changed mechanical property of $316 \mathrm{~L}$ austenitic stainless steel through different cold-work hardening. The investigated results indicate the material mechanical properties and the micro-indentation morphological change have evidently relevance, and the material mechanical parameters, such as the yield stress $\sigma_{y}$, the strain hardening exponent $n$ and others could be conveniently and effectively obtained by the proposed approach in this paper.
\end{abstract}

He Xue

xuehe@xust.edu.cn

1 School of Mechanical Engineering, Xi'an University of Science and Technology, Xi'an 710054, China

2 Xi'an Special Equipment Inspection Institute, Xi'an 710065, China

Department of Industrial and Manufacturing Systems Engineering, The University of HongKong, HongKong 999077, China
Keywords: Structural integrity assessment - Micro-indentation test - Numerical testing inversion analysis - Local material mechanical property

\section{Introduction}

Manufacturing mechanical structures process including welding and other hot or cold has been broadly adopted in industrial field [1-2]. It is been reported the mechanical property of metal materials will be changed after the cold or hot processing [3-4]. Because the local area involved in hot and cold processing is easy to occur flaw and failure, it is a key area for structural integrity analysis [5]. To obtain the precise mechanical properties of these local structure materials for the structural integrity analysis will be contribute to the further understanding of manufacturing processing [6-7].

It is of great practical significance to develop a test and calibration method to obtain the mechanical property parameters and distribution law of inhomogeneous welded joint materials [8]. Indentation test has been widely used as a non-destructive testing method which does not affect the continued service of equipment and is easy to operate [9-10]. Scholars have done research works on the measurement of mechanical property by indentation method [11-12]. As early as 1961, Stillwell and Tabor [13] proposed to determine the mechanical properties by using the elastic recovery generated through the indenter to press into the material. Bulychev et al. [14] measured the contact area through the unloaded part of the load-displacement curve, which laid the foundation for the later indentation hardness test. Tabor [15] studied the representative strain of the indentation plastic zone and obtained a series of relations, which played an important role in the subsequent research on the indentation method to characterize the stress and strain. Das et al. [16] studied the constitutive relationship and strength properties of two 
high-strength low-alloy steels under different pre-strains by continuous ball indentation method. Wei ZK et al. [17-18] used nano-indentation to study the stress-strain relationship of metal thin film materials, and carried out detailed characterization of the mechanical properties of different metal materials. Shen Lei et al. [19] used the indentation method to accurately measure the residual stress and established the relationship between the indentation bulge and the residual stress. Wu Shengbao et al. [20-21] used continuous ball indentation tests to characterize the mechanical properties of different metal materials in detail. Pamnanil et al. [22] studied the mechanical properties of the weld area with different welding methods in the high-strength and low-alloy steel structure by using the ball indentation test. These researches indicate that it is possible to obtain material property by an indentation test and analysis.

The complex thermal cycle in the welding will cause the major changes in the micro-structure and chemical composition of the material in welded joint, which also would be produce a complicated local stress state in welded joint. To represent the effect of the hot or cold processing on materials, the change of local material mechanical properties is performed by the different degrees of tensile deformation in this paper [23-24]. Thus an approach to obtain the material mechanical properties combined with the ball indentation test and finite element inversion to characterize the mechanics of $316 \mathrm{~L}$ austenitic stainless steel is discussed and studied.

\section{Theoretical Principle}

Under the action of external force, the metal material will undergo rapid and instantaneous elastic-plastic deformation [25]. Austenitic stainless steel and nickel-based alloys are widely used in nuclear power structures. The stress-strain relationship curve of this kind of metal can be represented by the stress-strain curve of a typical Linear Elastic-Power hardening material. In the elastic deformation stage, there is a linear correlation between stress and strain. In the plastic deformation stage, there is a power-rate relationship between stress and strain, called Hollomon relationship.

For the metal materials with hardening characteristic [26], the stress-strain curve can be defined as:

$$
\begin{gathered}
\boldsymbol{\sigma}=\left\{\begin{array}{cc}
\boldsymbol{E} \boldsymbol{\varepsilon} & \left(\sigma \leq \sigma_{y}\right) \\
K \boldsymbol{\varepsilon}^{\boldsymbol{n}}=\boldsymbol{E} \boldsymbol{\varepsilon}_{y}^{1-\boldsymbol{n}} \boldsymbol{\varepsilon}^{\boldsymbol{n}}\left(\sigma \geq \sigma_{y}\right)
\end{array}\right. \\
\boldsymbol{\varepsilon}=\boldsymbol{\varepsilon}_{y}+\boldsymbol{\varepsilon}_{p}
\end{gathered}
$$

where $\sigma_{y}$ is initial yield stress, $\boldsymbol{\varepsilon}$ is total strain, $\boldsymbol{\varepsilon}_{y}$ is initial yield strain, $\boldsymbol{\varepsilon}_{p}$ is plastic strain, $\boldsymbol{E}$ is the Young's modulus of material, $K$ is strength factor, $\boldsymbol{n}$ is the strain hardening exponent.

When $\sigma>\sigma_{y}$, the plastic stress $\sigma$ can be expressed by

$$
\boldsymbol{\sigma}=\boldsymbol{\sigma}_{y}\left(1+\frac{\boldsymbol{E}}{\boldsymbol{\sigma}_{y}} \boldsymbol{\varepsilon}_{p}\right)^{\boldsymbol{n}}
$$

The micro-nano indentation test mainly includes two stages of loading and unloading. In the loading phase, the indentert enters the surface of sample, the area will undergo elastic deformation. As the applied load gradually increases, the area with the largest elastic deformation will begin to enter the elastoplastic stage, where plastic deformation occurs [27].

The indentation method is used to obtain the mechanical properties of materials is Oliver-Pharr method [28]. A large number of test studies have shown that the load-depth curve is mainly used to obtain parameters such as hardness and elastic modulus of the material. The mechanical properties of the plastic stage are mainly obtained through the dimensional method. The typical load-depth curve about indentation test is shown in Figure 1. Taking the spherical indenter for the indentation test, Figure 2 shows a schematic diagram of indentation profile geometry of the test material.

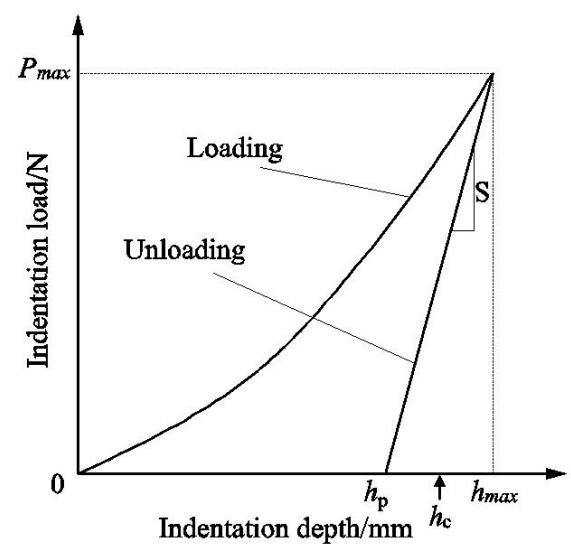

Figure 1 The typical load-depth curve

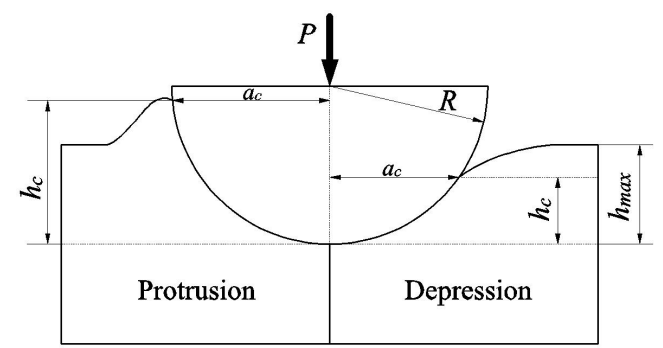

Figure 2 A schematic diagram of indentation profile geometry

In Figure 1 and Figure 2, $h_{\max }$ is the maximum depth value in the load-depth curve, $P_{\max }$ is the maximum load 
value, $S$ is the highest slope value of the unloading curve, $h_{p}$ is the residual indentation depth, $h_{c}$ is the contact depth value in the indentation process, $a_{c}$ is the contact radius in the indentation test, and $R$ is the ball indenter radius.

For a given shape of the indenter, the hardness value of the material can be obtained by

$$
\boldsymbol{H}=\frac{P_{\max }}{A}
$$

where $A$ is indentation contact area, and $A=2 \pi r h_{c}$.

For the elastic contact theory, ignore the influence of microscopic materials in the direction and size effect errors, the impact of border effects, and the geometric size of the gauge length section of the sample is much larger than the maximum indentation depth. The surface of the sample is a geometric plane, and is considered to be an isotropic material, such as

$$
E_{I T}=\frac{1-v^{2}}{\frac{1}{E_{r}}-\frac{1-v_{i}^{2}}{E_{i}}}
$$

where $E_{I T}$ is the Elastic modulus of the sample material, $v$ is the Poisson's ratio of the sample material. $E_{i}$ is the Elastic modulus of the indenter material, $v_{i}$ is the Poisson's ratio of the indenter material. Diamond is usually selected as the indenter material, where $E_{i}=1140 \mathrm{GPa}, v=0.07$.

In the study of plastic parameter identification, the optimization method is usually used to calculate the plastic mechanical parameters in the indentation process. Through indentation test simulation of a large number of materials with different parameter combinations, optimize and fit the input parameters and output results, establish the relationship between press-in measurable parameters and material parameters, and solve the required mechanical parameters. Where

$$
\log P=\log \left[2.8 \pi k c^{n+2}\left(\frac{0.2}{R}\right)^{n}\right]+m \log a
$$

where $a=\sqrt{2 R h-h^{2}}, m=\boldsymbol{n}+2$, and $n$ can be calculated from the slope of $\log P$ and $\log a$ curve.

To simplify the relationship between the analysis parameters and the identification parameters, and reduce the sensitivity of test errors, it has become a concern for this type of method. The accuracy and stability of the analysis method and the comparison verification with the uniaxial tensile test results are important links in the identification of plastic mechanical properties.

For the ball indenter, $\mathrm{T}$ Zhang established the relationship between $\boldsymbol{\sigma}_{y}$ and $\boldsymbol{W}_{u} / \boldsymbol{W}_{t}$. D Ma established the relationship between $\boldsymbol{\sigma}_{b}$ and $\boldsymbol{W}_{u} / \boldsymbol{W}_{t}$ [29]. Where $\boldsymbol{W}_{u}$ is unloading work, $\boldsymbol{W}_{t}$ is the total work from loading to complete unloading.

Based on the description of the related literature on the relationship between the work obtained by the load-depth curve and the mechanical properties of the material, the paper focuses on the relationship between unloading work and total work to predict material strength performance. The load-depth curve is composed of plastic work and elastic work. The sum of the two is the total indentation work. The schematic diagram of the composition is shown in Figure 3.

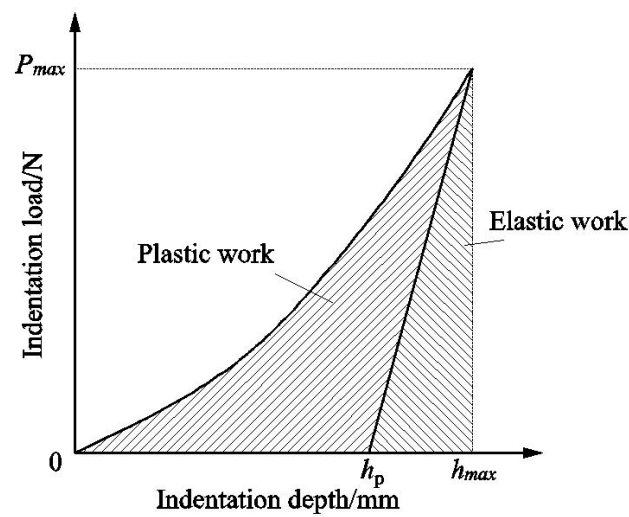

Figure 3 Composition of indentation work

The physical quantities involved in the pressing process include material parameters $\left(\boldsymbol{E}, v, \boldsymbol{\sigma}_{y}, \boldsymbol{n}\right)$, indenter geometric parameters $(R)$, control variable $\left(h, h_{\max }\right) . E$ and $h$ are selected as basic quantities, and the indentation loads $P, \boldsymbol{W}_{u}, \boldsymbol{W}_{t}$ are expressed by the basic quantities.

In the loading stage, the load $P$ can be expressed as

$$
P=\boldsymbol{f}_{F}\left(\boldsymbol{E}, v, \boldsymbol{\sigma}_{y}, \boldsymbol{n}, R, h\right)
$$

According to the definition of total indentation work, where

$$
\boldsymbol{W}_{t}=\int_{0}^{h_{\max }} P d h=\frac{\boldsymbol{E} h_{\max }^{3}}{3} \prod_{1}\left(\frac{\boldsymbol{\sigma}_{y}}{\boldsymbol{E}}, v, \boldsymbol{n}, R\right)
$$

The unloading work can be expressed as

$$
\boldsymbol{W}_{u}=\int_{h_{p}}^{h_{\max }} P d h=\boldsymbol{E} h_{\max }^{3} \prod \prod_{2}\left(\frac{\boldsymbol{\sigma}_{y}}{\boldsymbol{E}}, v, \boldsymbol{n}, R\right)
$$

Through the Eq. (7), Eq. (8) and Eq. (9), the relationship between unloading work and total indentation work can be obtained as 


$$
Y=\frac{\boldsymbol{W}_{u}}{\boldsymbol{W}_{t}}=\prod_{3}\left(\frac{\boldsymbol{\sigma}_{y}}{\boldsymbol{E}}, v, \boldsymbol{n}, R\right)
$$

\section{Indentation Test}

\section{1 Sample Preparation}

In this paper, $316 \mathrm{~L}$ austenitic stainless steel is processed into standard tensile specimens for testing. The geometric dimensions of the specimens are shown in Figure 4. The specimens is stretched to the gauge length of the sample to $2 \mathrm{~mm}, 4 \mathrm{~mm}, 6 \mathrm{~mm}$ respectively by using the tensile testing machine, that is, the tensile elongation are $10 \%, 20 \%$, and $30 \%$, for expressing the changes in the mechanical properties of materials by hot and cold processing.

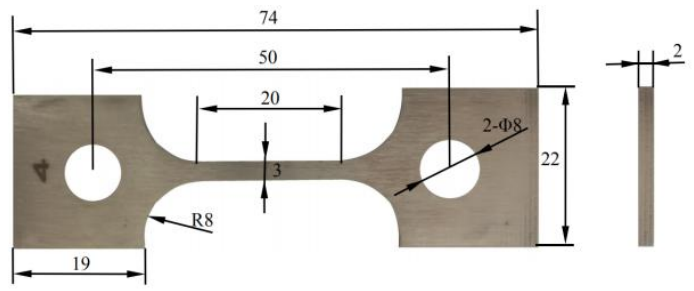

Figure 4 Plate-shaped tensile specimen

To remove the scratches on the surface and avoid the influence of surface roughness of the sample on the test results, the surface of the sample is evenly polished with 600\#, 1000\#, 1500\#, 2000\# waterproof abrasive paper before the test, and replaced different types of waterproof abrasive paper, the sample needs to rotate $90^{\circ}$. After the sanding process is completed, use the metallographic polishing machine to polish the sample, the particle size is $1 \mathrm{~W}$, the sample scratches are not obvious after polishing to the microscope.

Figure 5a shows the engineering stress-strain curve of 316L austenitic stainless steel with different cold working rates obtained through tensile experiments. The engineering stress-strain curve obtained is transformed into a true stress-strain curve by Eq. (11) and Eq. (12), as shown in Figure 5b.

$$
\begin{gathered}
\varepsilon_{t}=\int_{l_{0}}^{l} \frac{d l}{l}=\ln \left(\frac{l}{l_{0}}\right)=\ln \left(1+\varepsilon_{e}\right) \\
\sigma_{t}=\sigma_{e}\left(1+\varepsilon_{e}\right)
\end{gathered}
$$

a

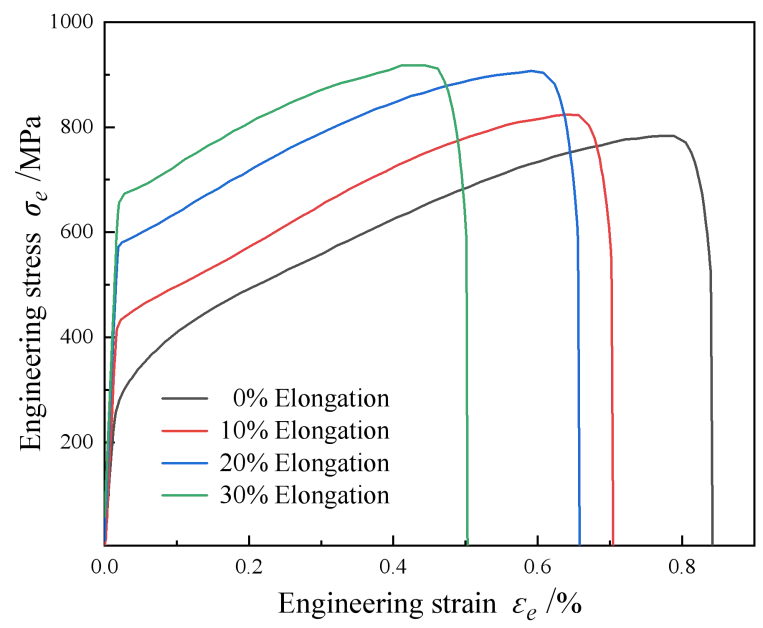

b

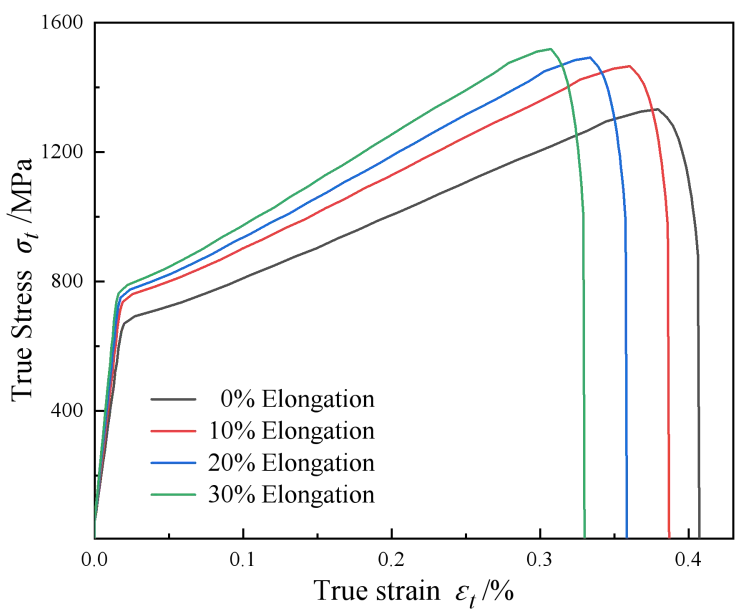

Figure 5 a Engineering stress-strain curve under different elongations; $\mathbf{b}$ true stress-strain curve under different elongations

\subsection{Parameter Setting of Indentation Test}

The indentation test platform has been modified on the basis of the electronic universal testing machine. Figure 6 shows the modified indentation test platform.

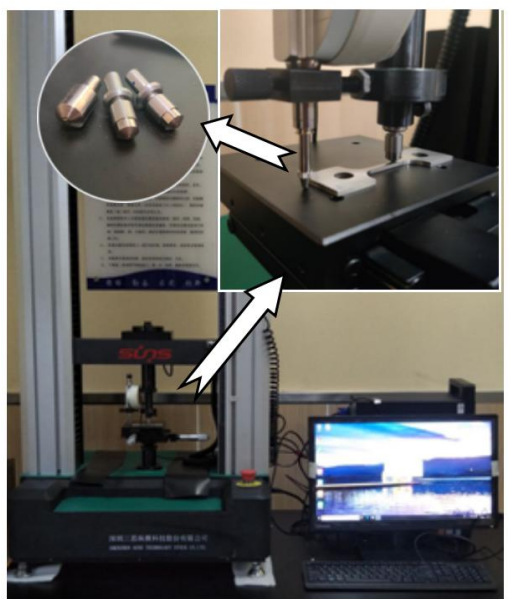

Figure 6 Indentation test system platform 
The specific modified ideas of the system are: the loading system adopts the electronic drive system of the electronic universal testing machine; the upper chuck of the testing machine is improved to be able to hold different types of indenters, and the lower chuck is changed to a sample platform that can be adjusted autonomously in two dimensions. A high-precision displacement sensor is installed on the side of the indenter to ensure synchronous acquisition of indentation depth. The accuracy of the high-precision displacement sensor is $0.5 \%$ of the full scale, and the resolution reaches $0.1 \mu \mathrm{m}$, and its accuracy satisfy the requirements of the indentation test.

The parameters for setting the indentation test are ball indenter radius, loading and unloading rate, loading and unloading load. The parameter settings of the test platform are as follows:

\section{(1) Ball indenter radius}

The ball indenter cannot be greater than one third of the tested sample. Considering the micro-loss characteristics of indentation testing technology, the cemented carbide spherical indenter with a radius of $0.25 \mathrm{~mm}$ be used in the indentation test, its dimensional accuracy is $\pm 0.001 \mathrm{~mm}$;

(2) Loading and unloading rate

The loading rate is set to $0.5 \mathrm{~mm} / \mathrm{min}$, and the unloading rate is set to $0.1 \mathrm{~mm} / \mathrm{min}$ in the indentation test. The loading process takes a long time, and more data needs to be collected. During unloading process, the elastic recovery of the indentation depth is mainly measured. Therefore, the unloading rate is set faster than the loading rate to ensure that the data collected during the entire indentation process is more appropriate.

(3) Loading and unloading load

The loading load of the indentation test is set to $300 \mathrm{~N}$, and the unloading load is set to $3 \mathrm{~N}$. The indentation load with an indentation depth of $0.1 \sim 0.2 \mathrm{~mm}$ needs to be between $150 \sim 300 \mathrm{~N}$. The unloaded load only needs to rebound after the indentation.

After setting the relevant parameters of the indentation system, the ball indentation test is on performed on tested materials with different elongations to obtain the indentation response results.

\section{Finite Element Model}

The finite element analysis software ABAQUS is used for indentation simulation test in this paper. The indentation process is completely symmetric,to facilitate the calculation and ensure the validity of the calculation results, this paper establishes a quarter of the three-dimensional model.
In the finite element inversion, the radius of the indenter, the thickness of the tested sample and the setting of related test parameters are all corresponding to the indentation test.

The Elastic modulus of $316 \mathrm{~L}$ austenitic stainless steel without pre-deformation, elongation of $10 \%, 20 \%$, and $30 \%$ is set to $210 \mathrm{GPa}$, and the Poisson's ratio is set to 0.3 . The material parameters in the plastic phase are the true stress-strain values obtained from uniaxial tensile tests. For the setting of the material parameters of the indenter, the Elastic modulus is set to $1 \times 1031 \mathrm{GPa}$, and the Poisson's ratio is set to 0.3 . In the indentation process, the indenter is set as a rigid body.

The finite element inversion adopts displacement loading method, the loading displacement in the loading analysis step is $0.2 \mathrm{~mm}$, the unloading displacement in the unloading analysis step is $0 \mathrm{~mm}$. The bottom of the tested sample is set in the $\mathrm{Y}$ direction, and the indenter is set to only move in the $\mathrm{Y}$ direction. The boundary condition constraints are shown in Figure 7.

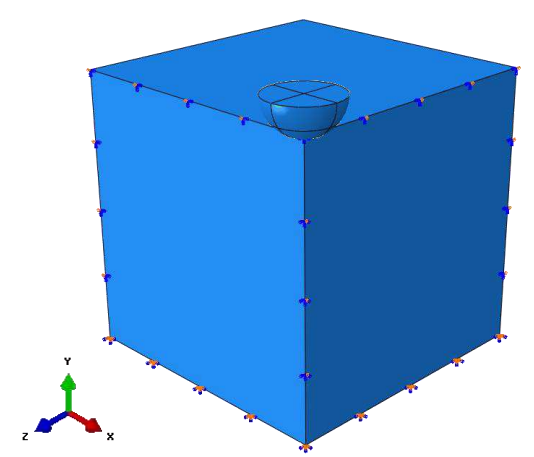

Figure 7 The boundary condition constraints

The quality and quantity of meshes in finite element calculations are critical to the results of calculations. The quality of the grid directly affects the accuracy of the simulation calculation. Reasonable division of the grid can effectively improve the computational efficiency of the finite element model. In this model, the size of the grid is a three-dimensional element grid (CPS4R), and the total number of division units is 44910 . The mesh of the contact part of the sample with indenter needs to be refined. The mesh refinement model is shown in Figure 8. 


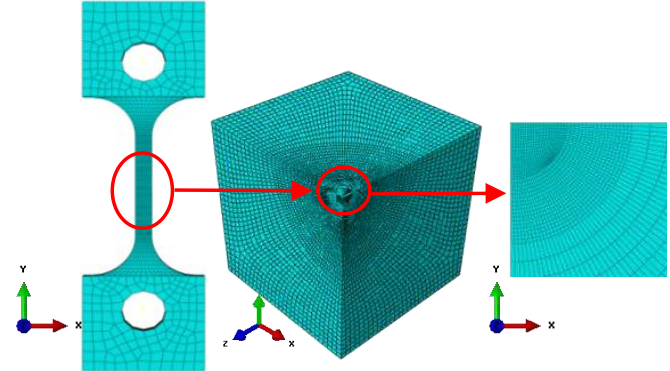

Figure 8 The mesh refinement model

The analysis steps in the finite element inversion are the preloading process, pressing-in process and unloading process. Setting the preloading step mainly requires the indenter to contact the sample to ensure the accuracy of displacement during the indentation process. The press-in step is set to displacement control. Setting the unloading step is mainly to calculate the mechanical properties of the material in the elastic phase. In the contact analysis, the friction coefficient $\mathrm{f}$ between the indenter and the sample is set to 0.3 .

\section{Results and Discussions}

\subsection{Indentation Test Results}

The load-depth curves obtained by the indentation test of austenitic stainless steel with no pre-deformation and $10 \%$, $20 \%, 30 \%$ elongations under the indentation load of $0 \sim 300 \mathrm{~N}$ are shown in Figure 9.

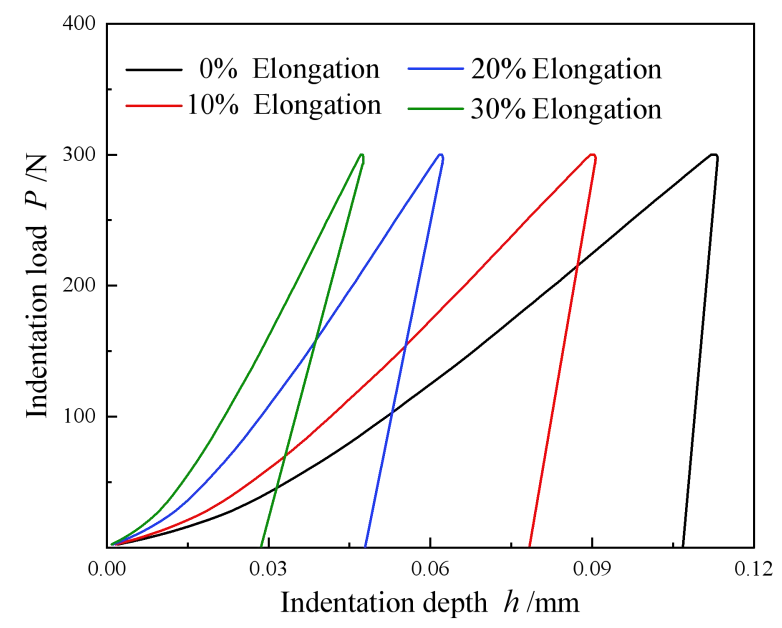

Figure 9 The load-depth curve obtained by indentation test under different elongations

It can be seen from Figure 9 that the loading and unloading trends of the curves are roughly the same. The slope of the curve in the loading phase gradually increases with the increase of the pre-deformation degree, indicating that the elastic model of the material also increases. During the unloading stage, the load value per unit area also gradually increases.
After the pre-deformation of the austenitic stainless steel material, the load-depth curve is clearly shifted to the left, indicating that the material becomes harder after pre-deformation, resulting in a smaller indentation response and a smaller residual indentation depth value.

According to the parameters of load-depth curve and the Oliver-Pharr method, the Elastic modulus and hardness values of 316 austenitic stainless steel under different elongations is shown in Figure 10. It can be seen that the Elastic modulus of the material gradually increases with the increase of the pre-deformation degree, but the change rate gradually decreases.

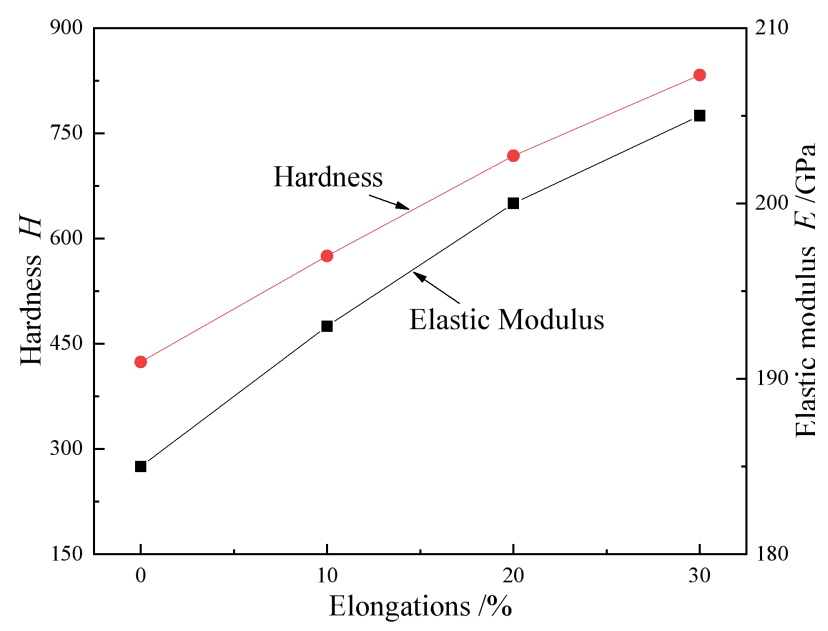

Figure 10 Change law of Elastic modulus and hardness under different elongations

When the material is not pre-deformed, the Elastic modulus is $185 \mathrm{GPa}$, and when the elongation is $30 \%$, the Elastic modulus is $203 \mathrm{GPa}$. For the indentation hardness, as the degree of pre-deformation gradually increases, the indentation hardness of the material also increases. When the material is not pre-deformed, the indentation hardness is $424 \mathrm{MPa}$, and when the elongation is $30 \%$, the indentation hardness reaches $833 \mathrm{MPa}$.

The indentation method obtains the plastic mechanical parameters of austenitic stainless steel mainly relies on the load-depth curve to calculate the yield strength, yield strain and hardening exponent.

For the calculation of yield strength, the area of the curve is used to estimate the energy in the indentation process, and then the strength value is calculated by the obtained energy. The hardening exponent is calculated by the self-similarity theory and the logarithmic slope between the load and the residual indentation area in the load-depth curve. The calculated unloading work, total indentation work, ratio and yield strength are shown in Table 1.

Table 1 Load-depth curve parameters of austenitic stainless 
$\underline{\text { steel and mechanical parameters with different elongations }}$

\begin{tabular}{lccccc}
\hline $\begin{array}{c}\text { Elongation } \\
\%\end{array}$ & $\begin{array}{c}\text { Unloading } \\
\text { work }\end{array}$ & $\begin{array}{c}\text { Total } \\
\text { work }\end{array}$ & $\begin{array}{c}\text { Yield } \\
\text { strength }\end{array}$ & $\begin{array}{c}\text { Tensile } \\
\text { strength }\end{array}$ & $\begin{array}{c}\text { Ratio } \\
W_{u}\end{array}$ \\
\hline 0 & 1.52 & 37.88 & 350 & 1331 & 0.040 \\
10 & 2.61 & 50.57 & 474 & 1362 & 0.052 \\
20 & 4.13 & 62.93 & 596 & 1401 & 0.066 \\
30 & 5.46 & 73.47 & 685 & 1452 & 0.074 \\
\hline
\end{tabular}

The yield strength and tensile strength in Table 1 are respectively linearly fitted to the ratio $Y$, and the fitted curve diagrams are shown in Figure 11a and $\mathrm{b}$. The correlation coefficient are $\mathrm{R}^{2}=0.998$ and $\mathrm{R}^{2}=0.999$, respectively. The the linear relations about Eq. (13) and Eq. (14) are obtained as

$$
\begin{gathered}
\boldsymbol{\sigma}_{y}=9682.38 Y-35.32647 \\
\boldsymbol{\sigma}_{b}=3632.4 Y+1180.8
\end{gathered}
$$

a

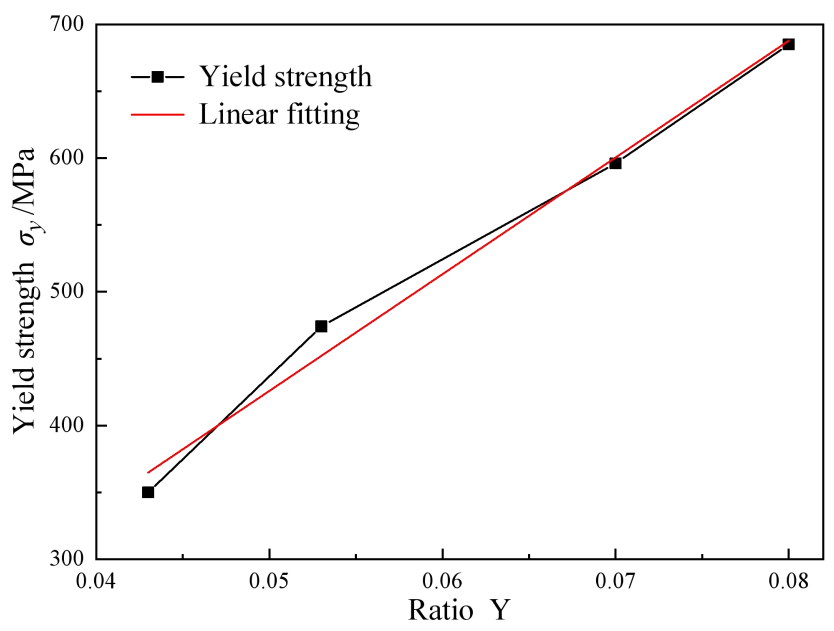

b

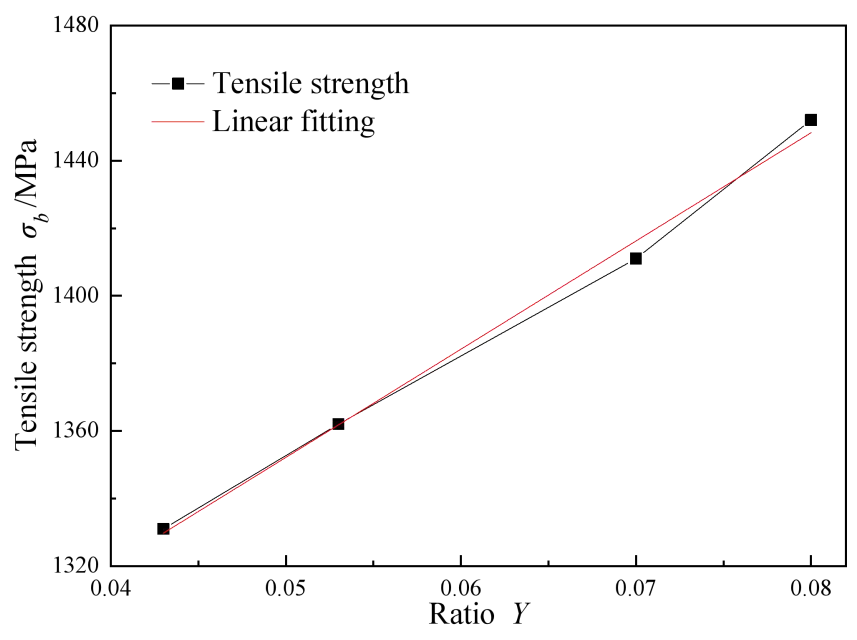

Figure 11 a Fitting curve of yield strength and ratio $Y$; b fitting curve of tensile strength and ratio $Y$

The hardening exponent values of materials with different elongations are shown in Figure 12. It can be seen that as the pre-deformation degree of austenitic stainless steel increases, the hardening exponent also increases.

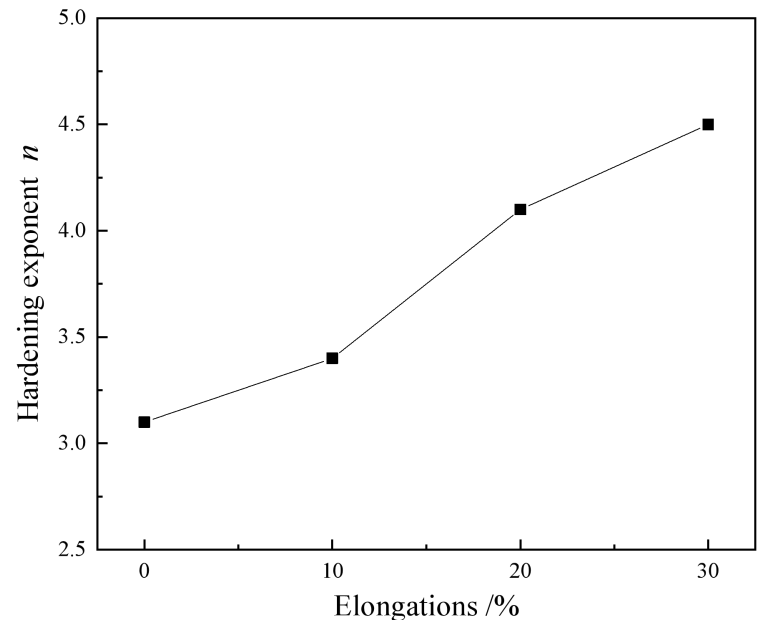

Figure 12 Change law of hardening exponent under different elongations

In addition, there is a linear increase relationship between the hardening exponent and the elongations. When the sample is not pre-deformed, the hardening exponent is 3.4. When the elongation is $30 \%$, the hardening exponent reaches 4.5. After the cold working process, the work hardening occurs inside the material, which leads to an increase in the plastic property of the material, so that the hardening exponent of the material also increases.

\subsection{Finite Element Inversion Analysis Results}

Figure 13 shows the load-depth curve of 316L austenitic stainless steel under four different elongations through indentation simulation.

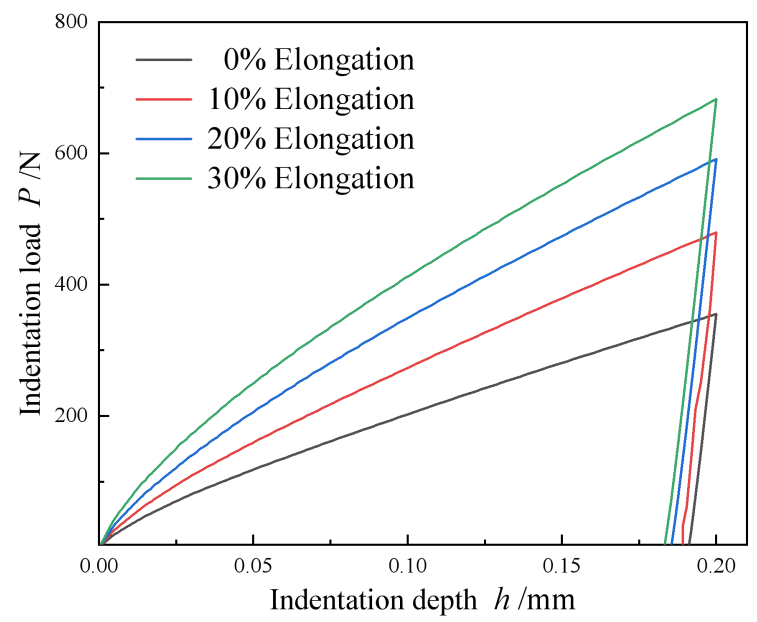


Figure 13 The load-depth curve obtained by finite element reversion under different elongations

It can be seen that the indentation simulation process of materials with different elongations is roughly the same. The loading curve during the pressing process shows a nonlinear trend. As the elongation increases, the required indentation force gradually increases. It shows that with the gradual increase of the elongation, the Elastic modulus and hardness of the tested material both increase.

In addition, the unloading displacements of the four unloading curves have obvious differences.
Pre-deformation has a certain effect on the rebound of the material. As the elongation increases, the residual depth of the sample gradually decreases. The material undergoes plastic deformation after pre-stretching, resulting in an increase in its yield strength and hardness. The load-depth curve obtained by the finite element inversion is consistent with the trend of the indentation test, so the accuracy of the indentation simulation is considered to be higher.

The indentation morphology of austenitic stainless steel with different elongations is obtained by finite element simulation. Figure $14 \mathrm{a}$ and $\mathrm{b}$ show the indentation process of $10 \%$ elongation.

a
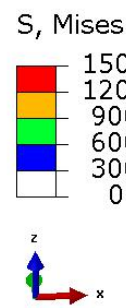

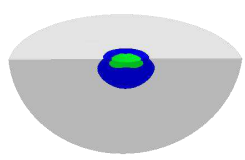

$\mathrm{t}=0.1 \mathrm{~s}$

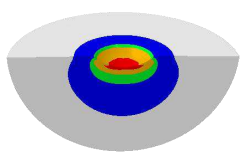

$\mathrm{t}=0.3 \mathrm{~s}$

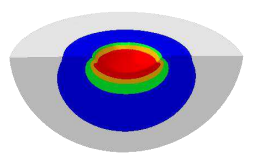

$\mathrm{t}=0.75 \mathrm{~s}$

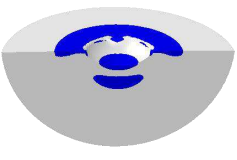

$\mathrm{t}=1.0 \mathrm{~s}$

b

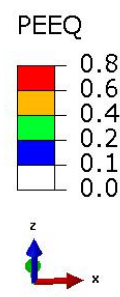

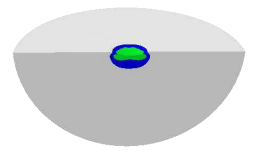

$\mathrm{t}=0.1 \mathrm{~s}$

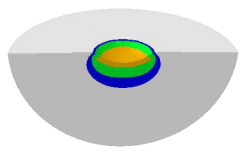

$\mathrm{t}=0.3 \mathrm{~s}$

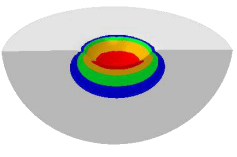

$\mathrm{t}=0.75 \mathrm{~s}$

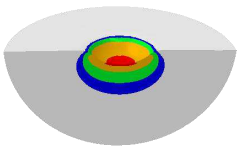

$\mathrm{t}=1.0 \mathrm{~s}$

Figure 14 a Mises stress of indentation process under 10\% elongation; $\mathbf{b}$ equivalent plastic strain (PEEQ) of indentation process under $10 \%$ elongation

Figure $14 \mathrm{a}$ of $\mathrm{t}=0.1 \mathrm{~s}, \mathrm{t}=0.3 \mathrm{~s}, \mathrm{t}=0.75 \mathrm{~s}$ show the loading stage of the pressing process. It can be seen that as the pressing depth increases, the maximum principal stress of Mises gradually increases. Figure $14 \mathrm{a}$ of $\mathrm{t}=1.0 \mathrm{~s}$ shows the unloading stage of the indentation test. Compared with the stress cloud diagram at the maximum depth of the loading stage, it can be seen that after unloading, the material has gone through the elastic recovery stage, and the maximum principal stress of Mises is reduced. Figure 14b shows the equivalent plastic strain (PEEQ) of the indentation process. During the loading phase, PEEQ increases as the depth of the indentation. After the indenter is pressed into the maximum indentation depth, the unloading begins. When the maximum depth is reached, the indenter begins to unload. The unloaded material passes through the elastic release stage, its strain and strain range are reduced.

The displacement increment on the same path of the material surface on the side in contact with the indenter is analyzed, as shown in Figure 15.

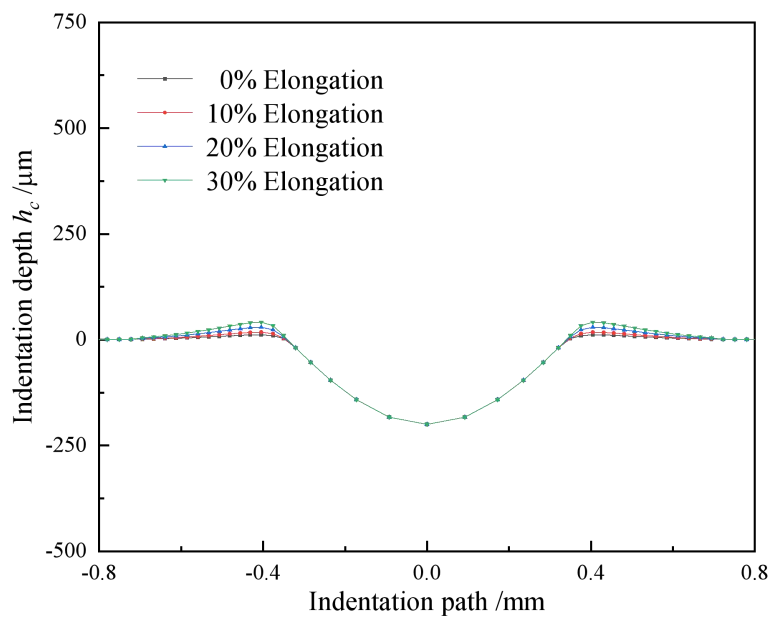

Figure 15 Comparison of maximum indentation morphology under different elongations 
It can be seen from the Figure 15 that the displacement increment trend of materials with different elongations on the indentation path is the same. The materials in contact with the area under the indenter will first produce elastic deformation because of the indenter. As the load continues to increase, the indenter will continue to press down, and the material will undergo plastic deformation, and the downward increment will gradually increase. The material in the area around the indenter gradually accumulated. The maximum protrusion of undeformed material is $28.603 \mu \mathrm{m}$, the maximum protrusion of $10 \%$ elongation is $29.954 \mu \mathrm{m}$, the maximum protrusion of $20 \%$ elongation is $34.418 \mu \mathrm{m}$, and the maximum protrusion of $30 \%$ elongation is $39.406 \mu \mathrm{m}$.

\subsection{Comparison of Results}

The mechanical properties of materials with different elongations obtained in the indentation test need to be verified. The results obtained in the uniaxial tensile test are the agreed true values.

Figure $16 \mathrm{a}$ and $\mathrm{b}$ show the comparison between the mechanical properties of austenitic stainless steel $316 \mathrm{~L}$ calculated by the indentation test and the uniaxial tensile test under the different elongation conditions.

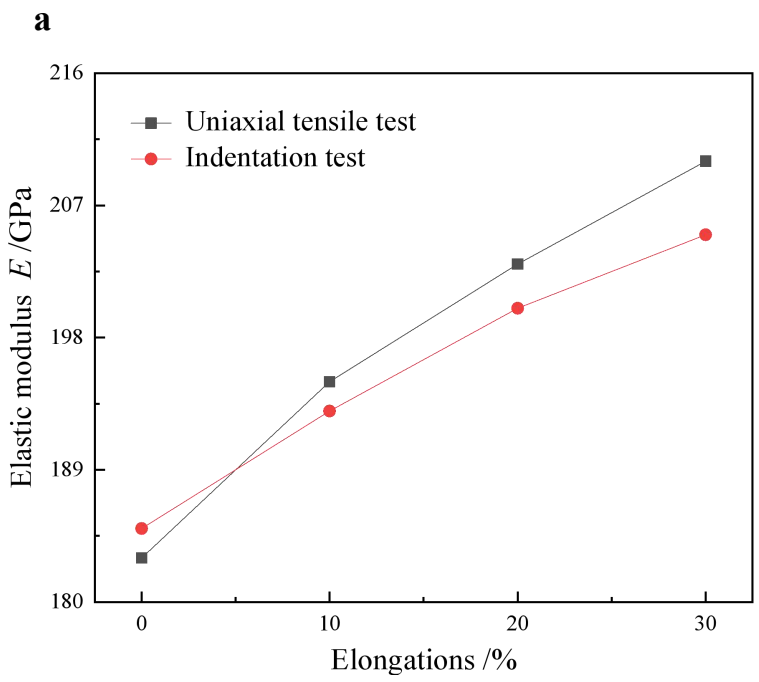

b

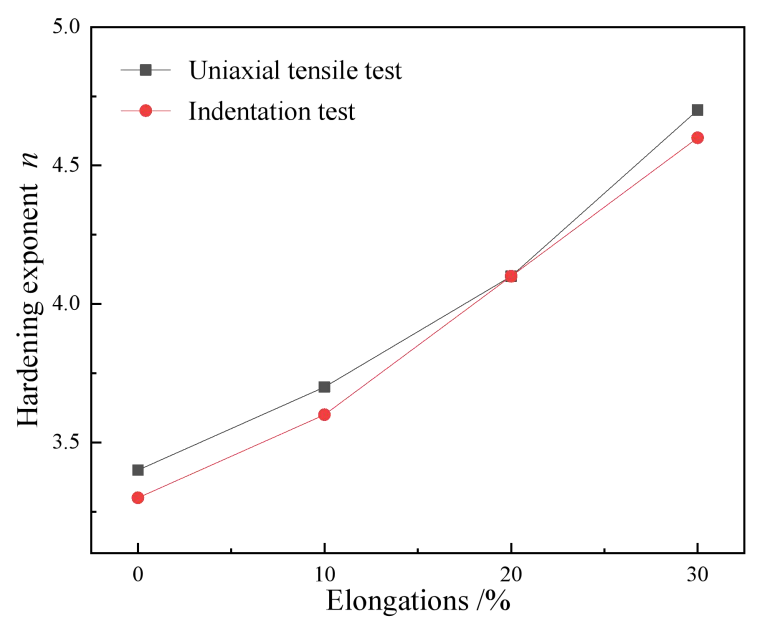

Figure 16 Comparison of mechanical parameters obtained by indentation test and tensile test under different elongations: a Elastic modulus; b hardening exponent

It can be seen from Figure 16 that the mechanical property parameters of austenitic stainless steel at different elongations obtained by the indentation test are relatively close to the uniaxial tensile test. The mechanical properties calculated by the indentation test have high accuracy and a small error range. The errors of elastic modulus are all less than $3 \%$. The errors of the hardening exponent are less than $5 \%$.

To verify the accuracy of the finite element model, it is necessary to verify the indentation test results obtained by the finite element method to ensure the accuracy of mechanical parameters. Figure $17 \mathrm{a}$ and $\mathrm{b}$ show the comparison of the deviation of the mechanical parameters calculated by the indentation test and the finite element method.

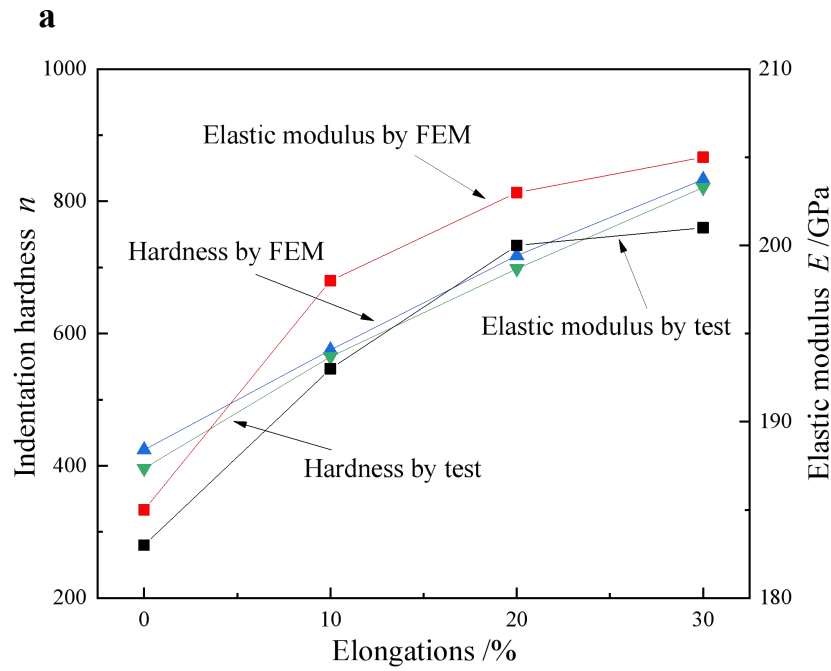




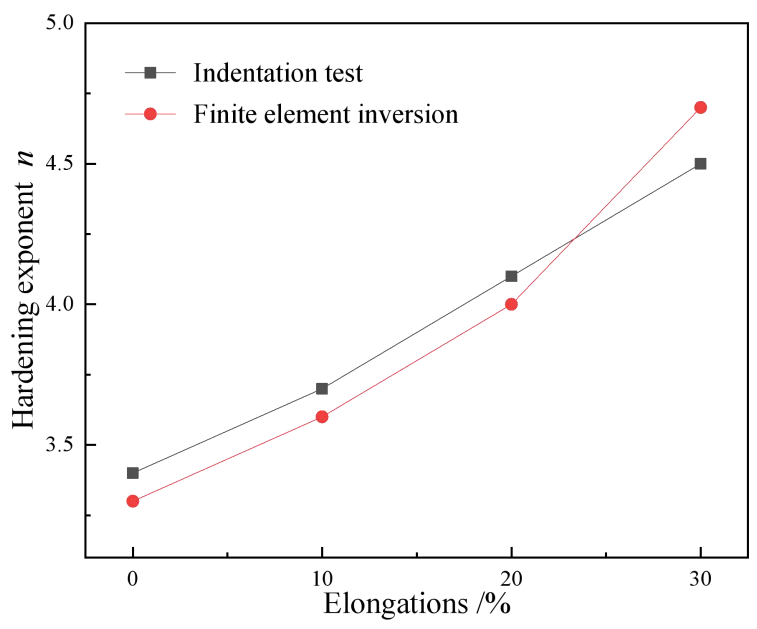

Figure 17 Comparison of mechanical parameters obtained by indentation test and finite element method with different elongations: a Elastic modulus and hardness; b hardening exponent

It can be seen from the Figure 17 that the mechanical properties have little difference between the indentation test and finite element simulation under different elongations, thereby the accuracy of the established finite element model is confirmed. The error of Elastic modulus are below $3 \%$, and the error of indentation hardness is about $5 \%$. The error of the hardening exponent is about $5 \%$, and the reason for the larger error is the small transition zone between the elasticity and plasticity of the stress-strain curve, but it is within the acceptable range.

\section{Conclusions}

This paper mainly uses the micron-level indentation test system built by the laboratory to perform indentation tests on austenitic stainless steel $316 \mathrm{~L}$ under different elongations, with the aid of finite element inversion analysis, the indentation process simulation was realized, and the mechanical performance parameters were compared. The following conclusions can be drawn from this study:

(1) A suitable test program was developed for indentation test, and the load-depth curves of austenitic stainless steel $316 \mathrm{~L}$ under different elongations were obtained. As the elongation increases, the curve shifts to the left, the resulting indentation response becomes smaller, and the residual indentation depth value becomes smaller.

(2) The indentation test model was established using the finite element software ABAQUS, and the relevant mechanical property parameters of materials with different elongations were obtained by inversion analysis. Comparing them with the indentation test, the deviations are all within 5\%, which ensures the accuracy of the finite element model.

(3) Compared with the test results obtained from the tensile test based on the plate-shaped tensile specimen, the deviations of the elastic-plastic material mechanical parameters, such as yield stress, Elastic modulus, hardening exponent and others are within $5 \%$ obtained through the indentation test and the finite element inversion analysis.

(4) It provides a reasonable and effective structural integrity evaluation to obtain the actual material mechanical property of the welding and other hot or cold working areas in key structures.

\section{Declaration}

\section{Acknowledgements}

No applicable.

\section{Funding}

Supported by National Natural Science Foundation of China (Grant No. 52075434).

\section{Availability of data and materials}

The datasets supporting the conclusions of this article are included within the article.

\section{Authors' contributions}

The author' contributions are as follows: HX was in charge of the whole trial; JH wrote the manuscript; JZ and YX assisted with sampling and laboratory analyses. All authors read and approved the final manuscript.

\section{Competing interests}

The authors declare no competing financial interests.

\section{References}

[1] S Guo, E H Han, H Wang, et al. Life prediction for stress corrosion behavior of 316L stainless steel elbow of nuclear power plant. Acta Metall Sin, 2017, 53(4): 455-464.

[2] M D Wu, D H Xiao, W B Chen, et al. Effect of cold rolling pre-deformation on microstructure and mechanical properties of new aluminium lithium alloy. Rare Metal Materials and Engineering, 2020, 49(9): 3251-3259.

[3] X Z Hou, W J Zheng, Z G Song, et al. The effect of cold working on mechanical behavior and microstructure of $316 \mathrm{~L}$ stainless steel. Journal of Iron and Steel Research, 2013, 25(7): 53-57.

[4] H Xue, K Li, S Wang, et al. Size effect analysis of hardness indentation of 316L austenitic stainless steel during cold working. China Mechanical Engineering, 2019, 30(1): 105-112.

[5] P L Andresen. A brief history of environmental cracking in hot water. Corrosion, 2019, 75(3): 240-253. 
[6] H Xue, Z C Zhuang, T Cao, et al. Analysis of relationship between Vickers hardness and yield stress of structural materials . Journal of Xi'an University of Science and Technology, 2017, 37(2): 274-279.

[7] V Sklenicka, K Kucharova, P Kral, et al. The effect of hot bending and thermal ageing on creep and microstructure evolution in thick-walled P92 steel pipe. Materials Science and Engineering, 2015(644): 297-309.

[8] Y Q Li, H Xue. Micro-mechanical state at SCC tip in nuclear key structure materials. Journal of Xi'an University of Science and Technology, 2016, 36(3): 380-384.

[9] S M Walley . Historical origins of indentation hardness testing. Materials Science and Technology, 2012, 28: 9-10, 1028-1044.

[10] D Tabor. Indentation hardness: Fifty years on a personal view. Philosophical Magazine A: Physics of Condensed Matter, Structure, Defects and Mechanical Properties, 1996, 74(5): 1207-1212.

[11] D D Zong, D Wang, W C Li, et al. Design of automatic leveling device based on marlin firmware desktop 3D printer. Industrial Control Computer, 2016, 29(4) :85-88.

[12] D C Patil, S A Kori, K Venkateswarlu, et al. Using ball indentation to determine the mechanical properties of an Al-7475 alloy processed by high-pressure torsion. Journal of Materials Science, 2013, 48(13): 4773-4779.

[13] N A Stillwellwe, D Tabor. Elastic recovery of conical indentation. Phys. Proc. Soc, 1961, 78(2): 169-179.

[14] S I Bulychev, V P Alekhin, M K Shorshorov, et al. Determining Young's modulus from the indenter penetraion diagram. Zavod. Lab, 1975, 41(9): 11137-11114.

[15] F M Haggag, L J Siefken. Effects of fuel rod length on in-core relocation of liquefied material. AIChE Symp. Ser, 1983, 79(225): 303-309.

[16] G Das, S Ghosh, S K Sahay, et al. Influence of pre-straining on mechanical properties of HSLA steel by using ball indentation technique. Zeitschrift Fur Metallkunde, 2004, 95(12): 1120-1127.

[17] B Zou, Z K Wei, K S Guan. Fature toughness valuation of seel by continuous ball indentation test. Journal of Materials Science and Engineering, 2016, 34(4): 577-580.

[18] Z K Wei, S B Wu, K S Guan. Fracture toughness of $16 \mathrm{MnR}$ steel evaluated by ball indentation method. Materials for mechanical engineering, 2016, 40(1): 32-34+38.

[19] L Shen, Y He, D Liu, et al. A novel method for determining surface residual stress components and their directions in spherical indentation. Journal of Materials Research, 2015, 30(8): 1078-1089.

[20] $\mathrm{S} \mathrm{B} \mathrm{Wu}, \mathrm{T} \mathrm{Xu}, \mathrm{C} \mathrm{Yu}$, et al. Measuring tensile properties of $16 \mathrm{MnR}$ steel by ball indentation technology. Materials for mechanical engineering, 2015, 39(1): 82-85.

[21] S B Wu, K S Guan. Finite element analysis of determining tensile properties of materials using ball indentation technique. Pressure Vessel Technology, 2012, 29(9): 33-38+49.

[22] R Pamnani, V Karthik, T Jayakumar, et al. Evaluation of mechanical properties across micro alloyed HSLA steel weld joints using automated ball indentation. Materials Science and Engineering, 2016, 651: 214-223.

[23] K Li, H Xue, Y H Cui, et al. Establishment and validation of stress-strain constitutive equation during cold working of 304 stainless steel. Journal of Plasticity Engineering, 2019, 26(2): 225-232.

[24] H Xue, J X He, W N Jia, et al. An approach for obtaining mechanical property of austenitic stainless steel by using continuous indentation test analysis. Structures, 2020, 28: 2752-2759.

[25] D L Shu. Mechanical properties of engineering materials. Beijing:
China Machine Press, 2013. (in Chinese)

[26] T H Zhang. Micro/Nano mechanical testing technology. Beijing: China Machine Press, 2004. (in Chinese)

[27] G M Pharr, W C Oliver, F R Brotzen. On the generality of the relationship among contact stiffness, contact area, and elastic modulus during indentation. Journal of Materials Research, 1992, 7(3): 613-617.

[28] Y T Cheng, C M Cheng. Relationships between hardness, elastic modulus, and the work of indentation. Applied Physics Letters, 1998, 73(5): 614-616.

[29] D Ma, T Zhang, C W Ong. Revelation of a functional dependence of the sum of two uniaxial strengths/hardness on elastic work/total work of indentation. Journal of Materials Research, 2006, 21(4): 895-903.

\section{Biographical notes}

He Xue, born in 1961, is currently an professor at Xi'an University of Science and Technology, China. He received his $\mathrm{PhD}$ degree in 1998 from Xi'an Jiaotong University, China. His research interests is safety evaluation of important mechanical structures.

Tel: +86-13088958007; E-mail: xuehe@xust.edu.cn

Jin-Xuan He, born in 1994, is currently a master candidate at School of Mechanical Engineering, $X{ }^{\prime}$ ' an University of Science and Technology, China. His research interests is safety evaluation of important mechanical structures.

Tel: +86-13572579708; E-mail: 84118631@qq.com

Jian-long Zhang, born in 1988, is currently an engineer at Xi'an Special Equipment Inspection Institute, China. He received his $\mathrm{PhD}$ degree in 2020 from Xi'an University of Science and Technology, China.

Tel: +86-13679269699; E-mail: 527449153@qq.com

Yu-xuan Xue, born in 1994, is currently a Phd candidate at Department of Industrial and Manufacturing Systems Engineering, The University of HongKong, China. His research interests is nanorobotics and micro-mechanics.

Tel: +852-68132457; E-mail: xueyuxuan@hku.hk 
Figures

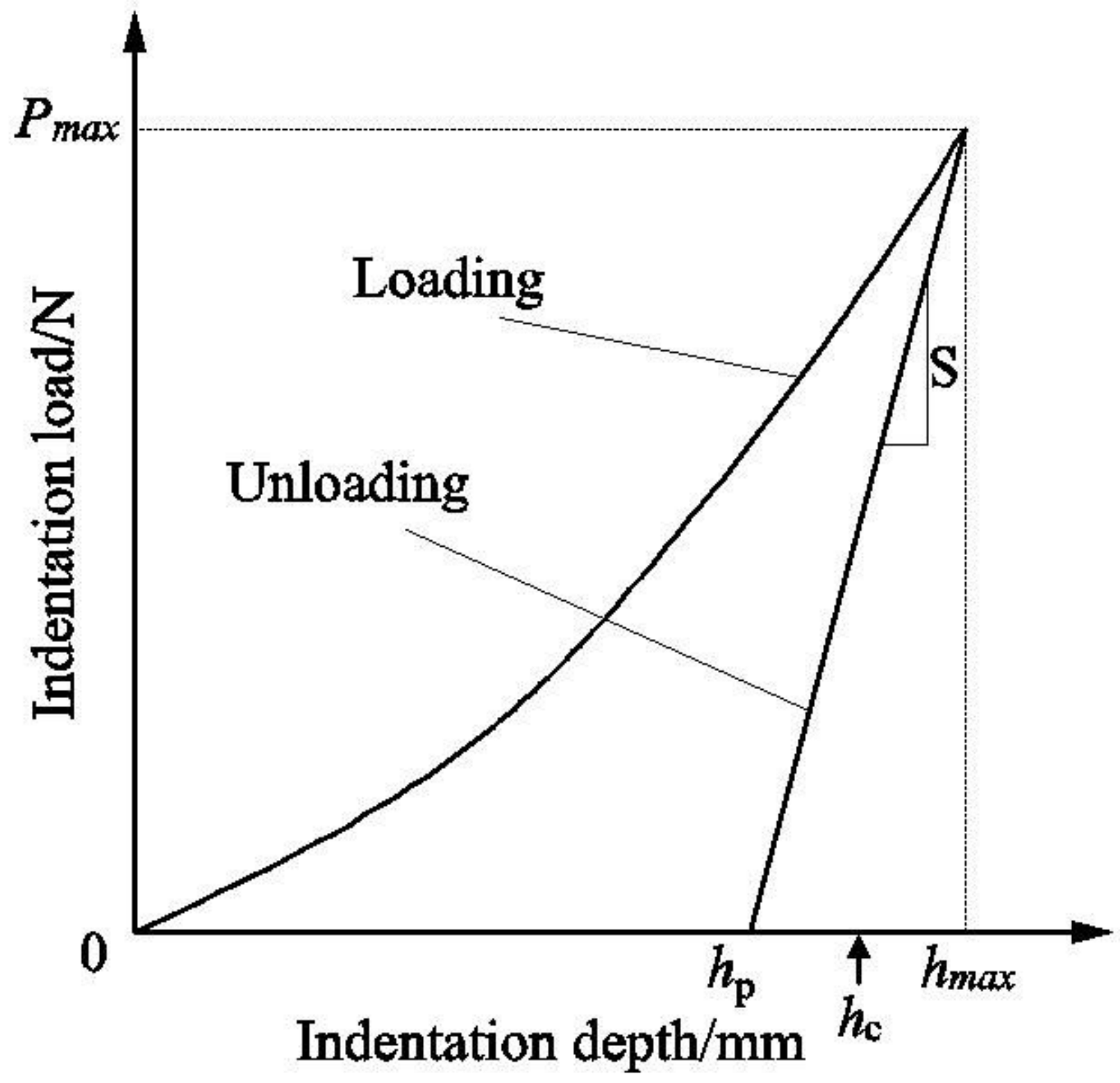

Figure 1

The typical load-depth curve. 


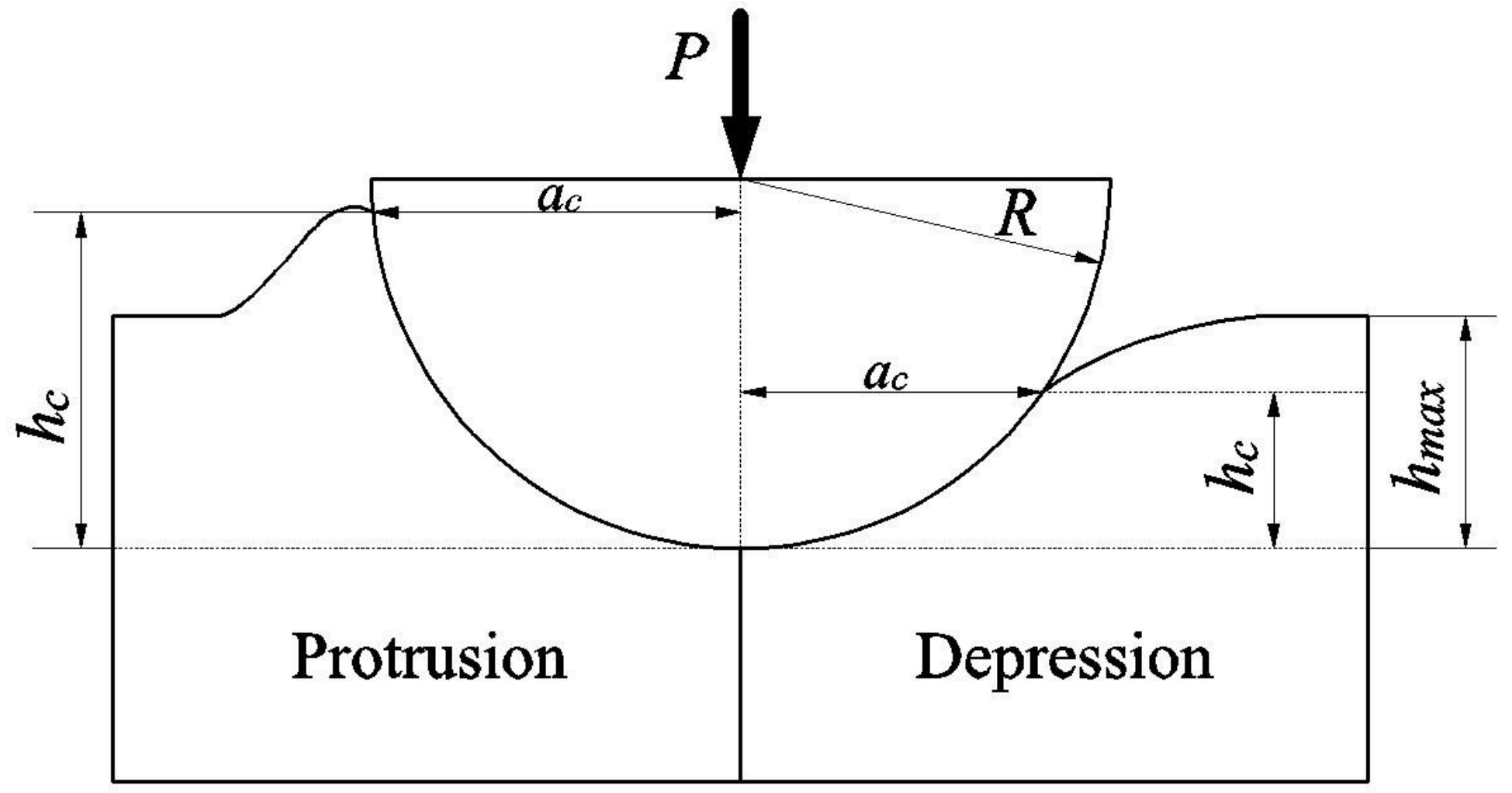

Figure 2

A schematic diagram of indentation profile geometry. 


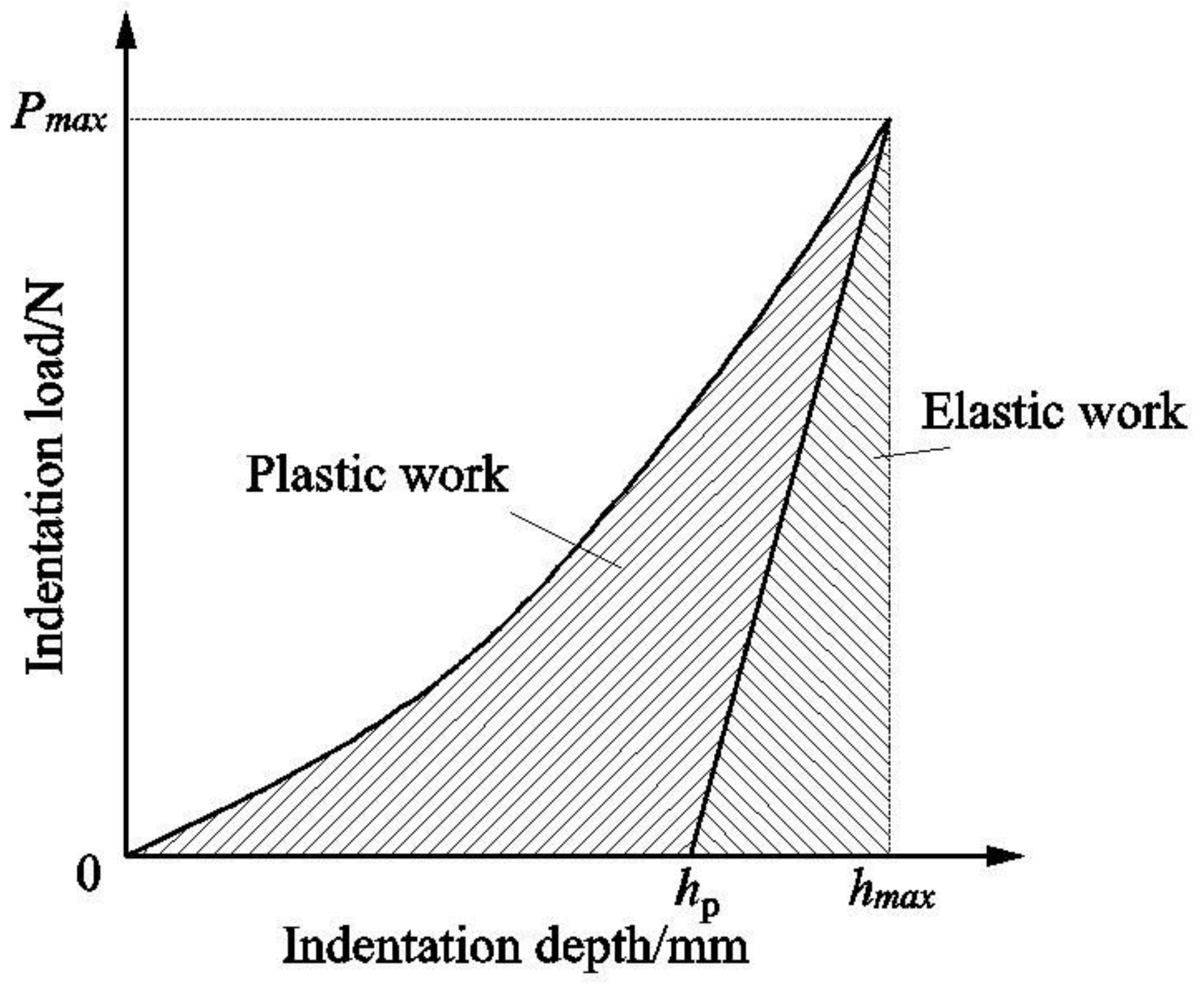

Figure 3

Composition of indentation work.

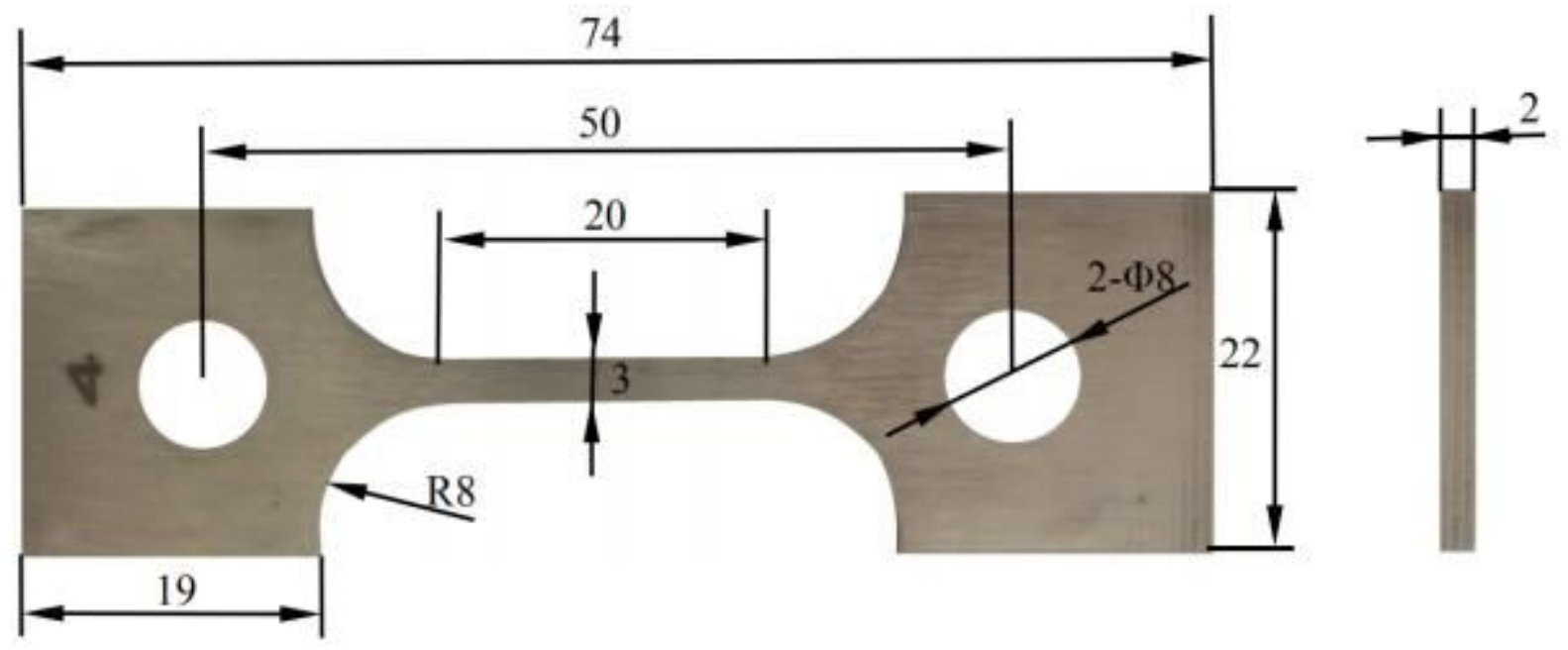


Figure 4

Plate-shaped tensile specimen.

$\mathbf{a}$

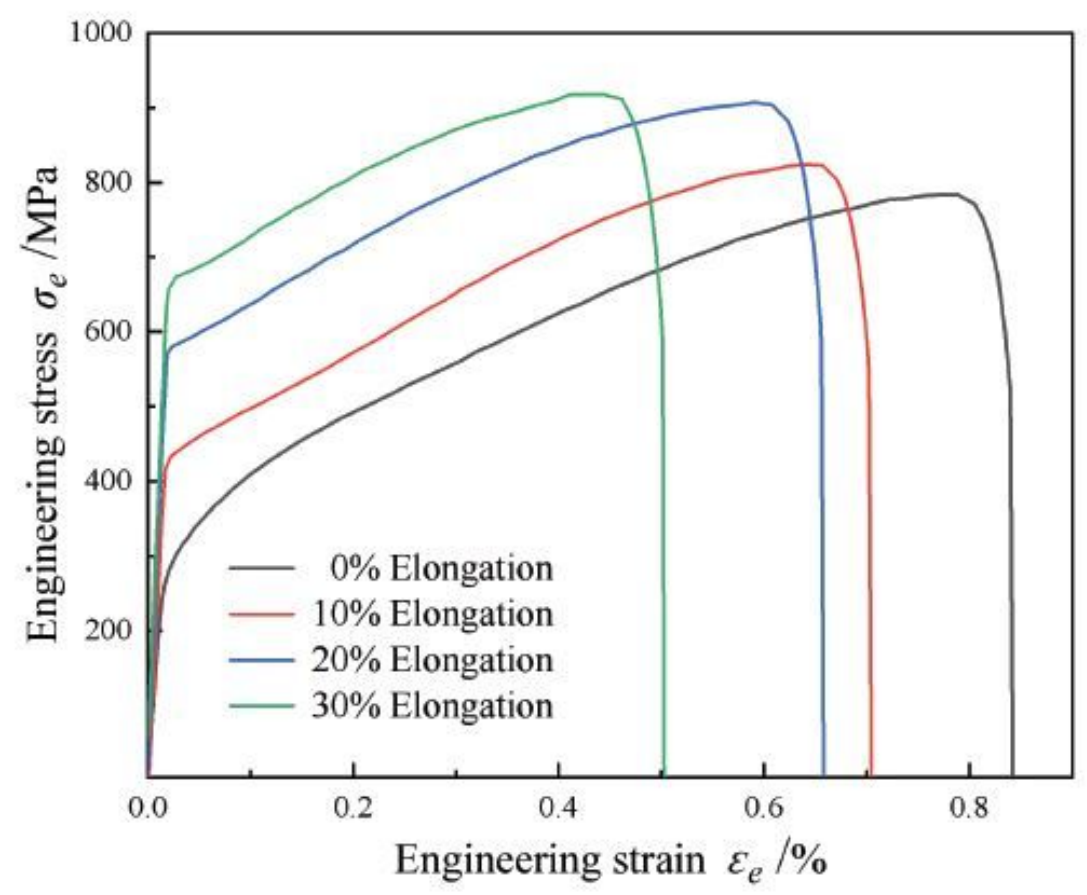

b

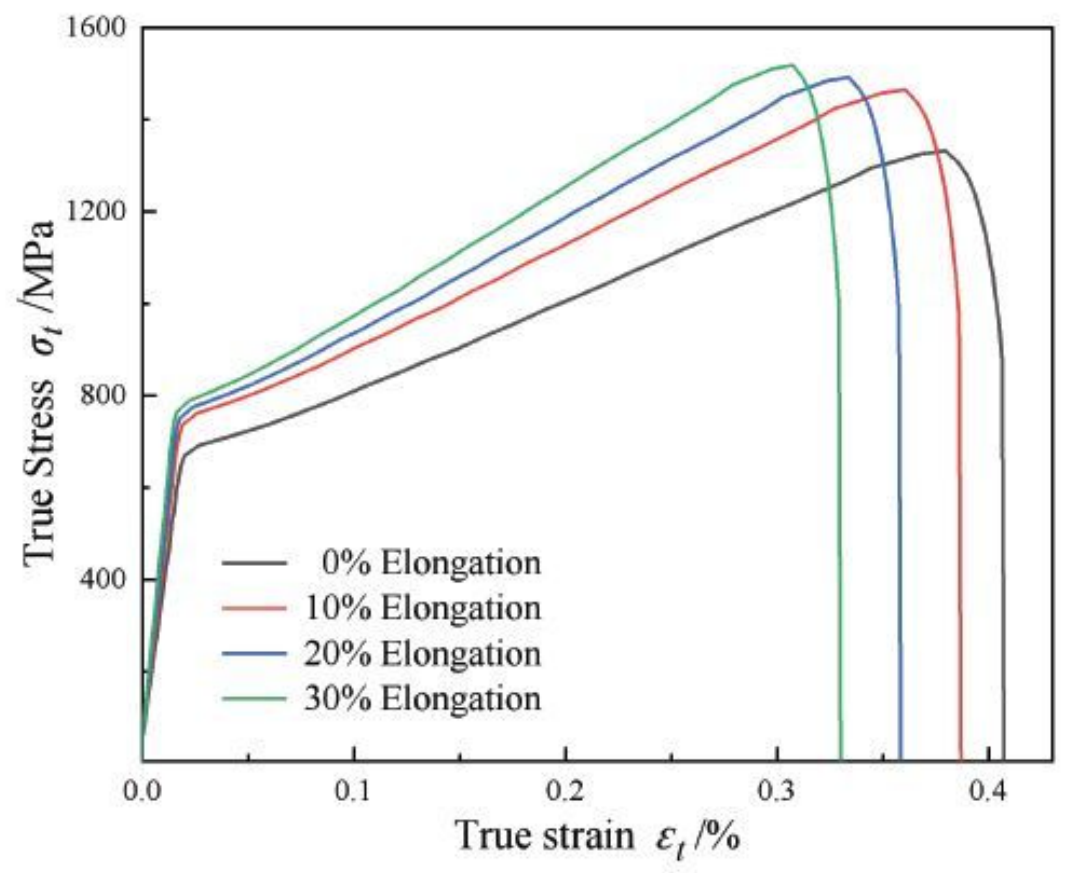

Figure 5

a Engineering stress-strain curve under different elongations; $b$ true stress-strain curve under different elongations. 


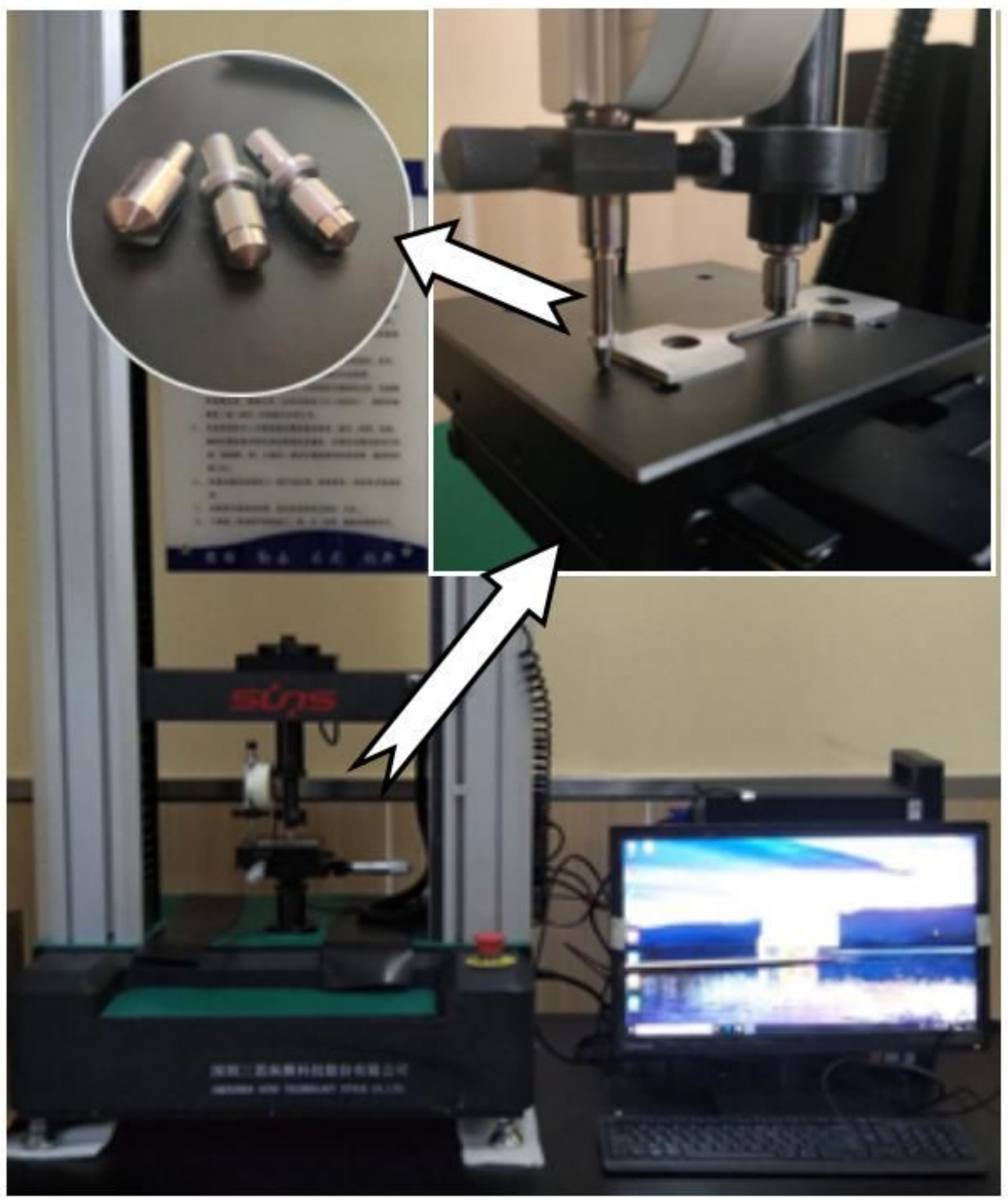

Figure 6

Indentation test system platform 


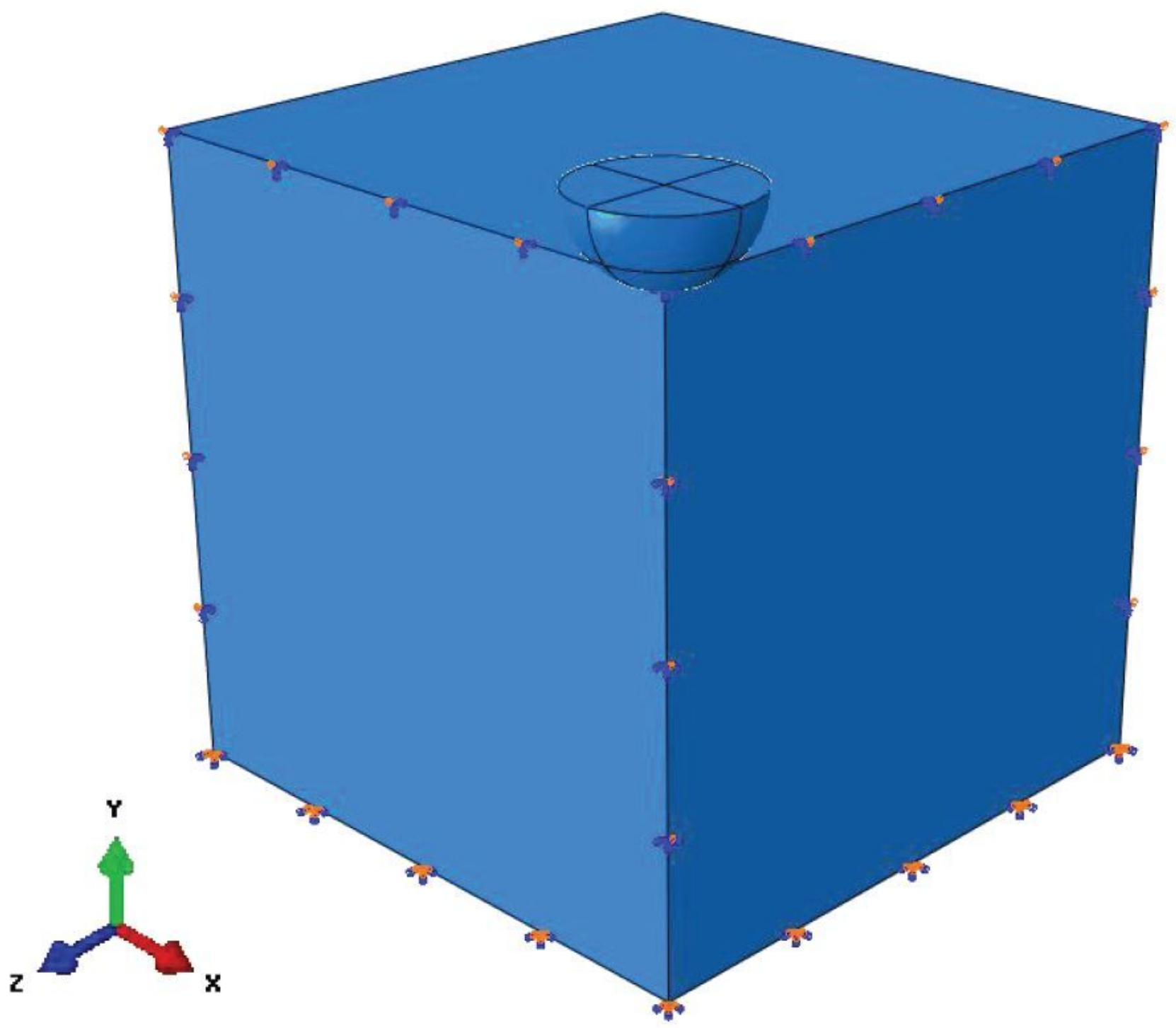

Figure 7

The boundary condition constraints 


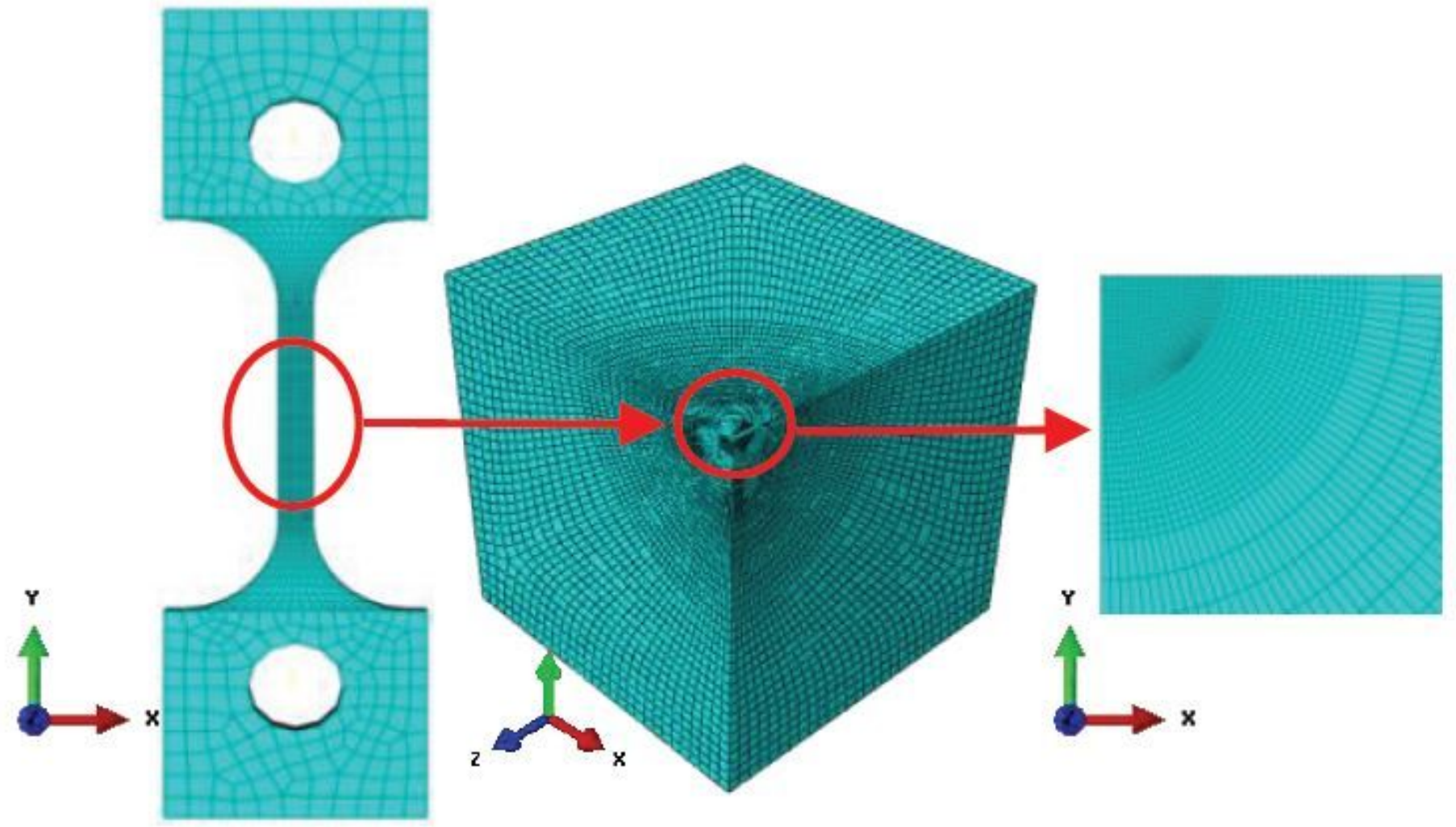

Figure 8

The mesh refinement model 


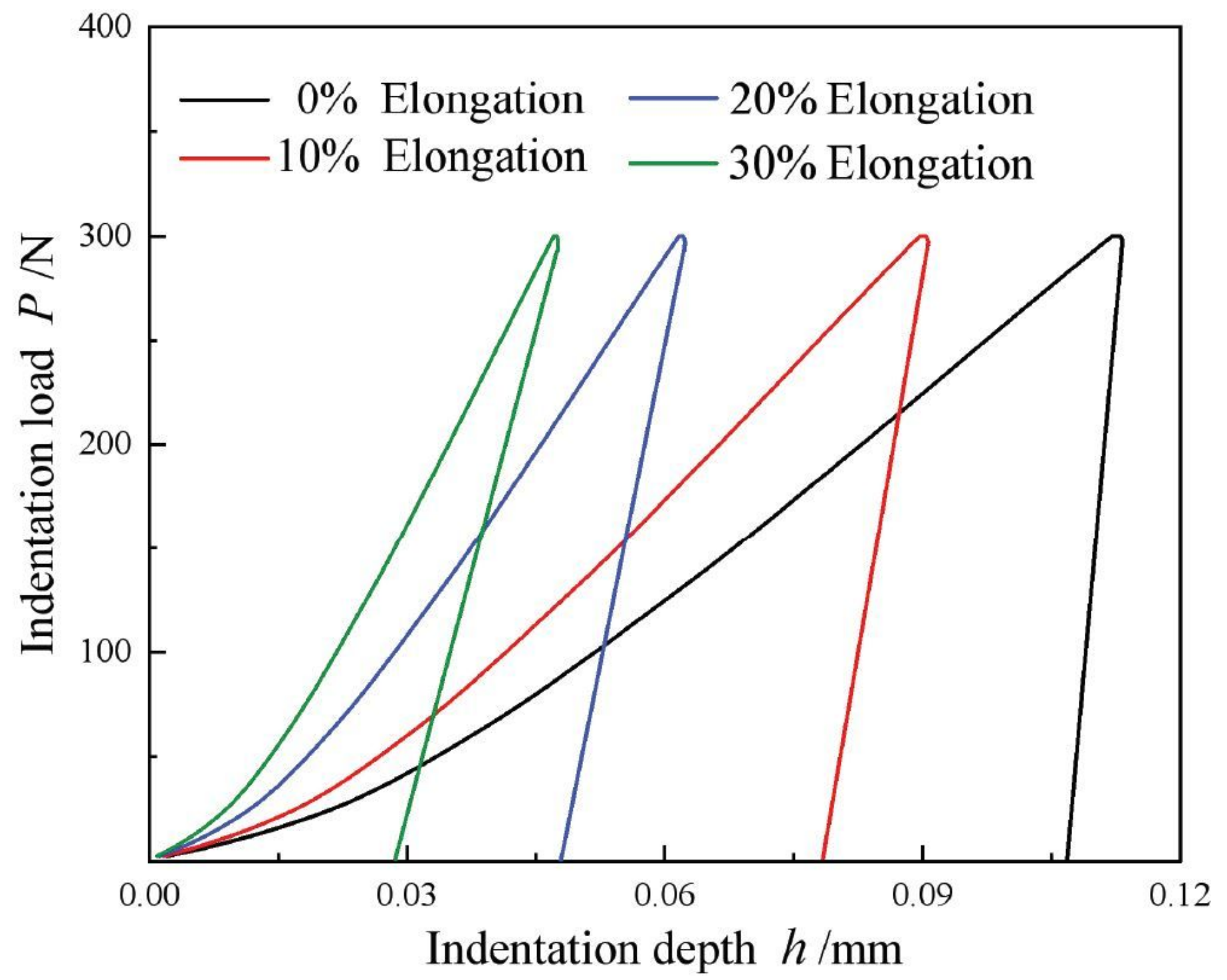

Figure 9

The load-depth curve obtained by indentation test under different elongations 


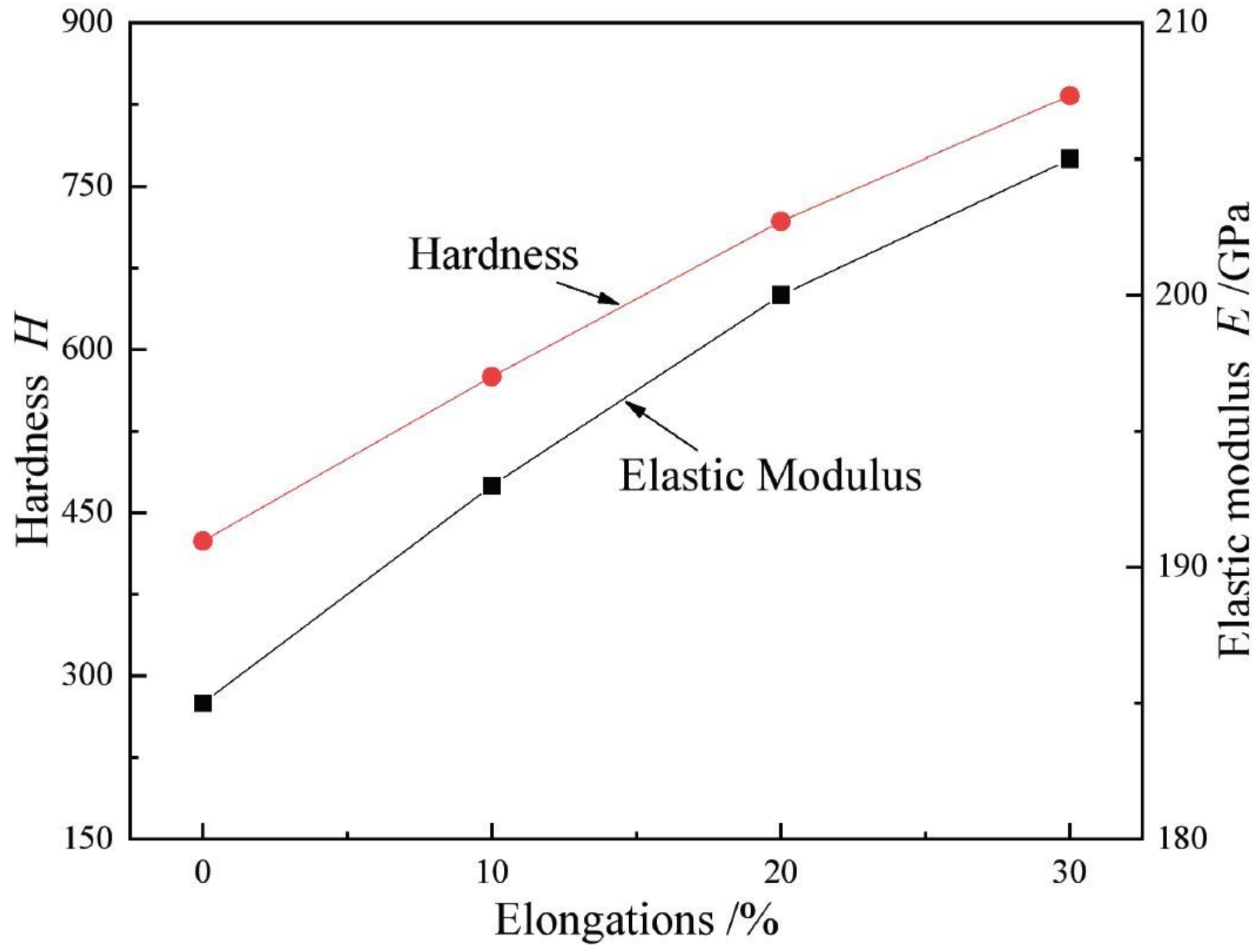

Figure 10

Change law of Elastic modulus and hardness under different elongations 


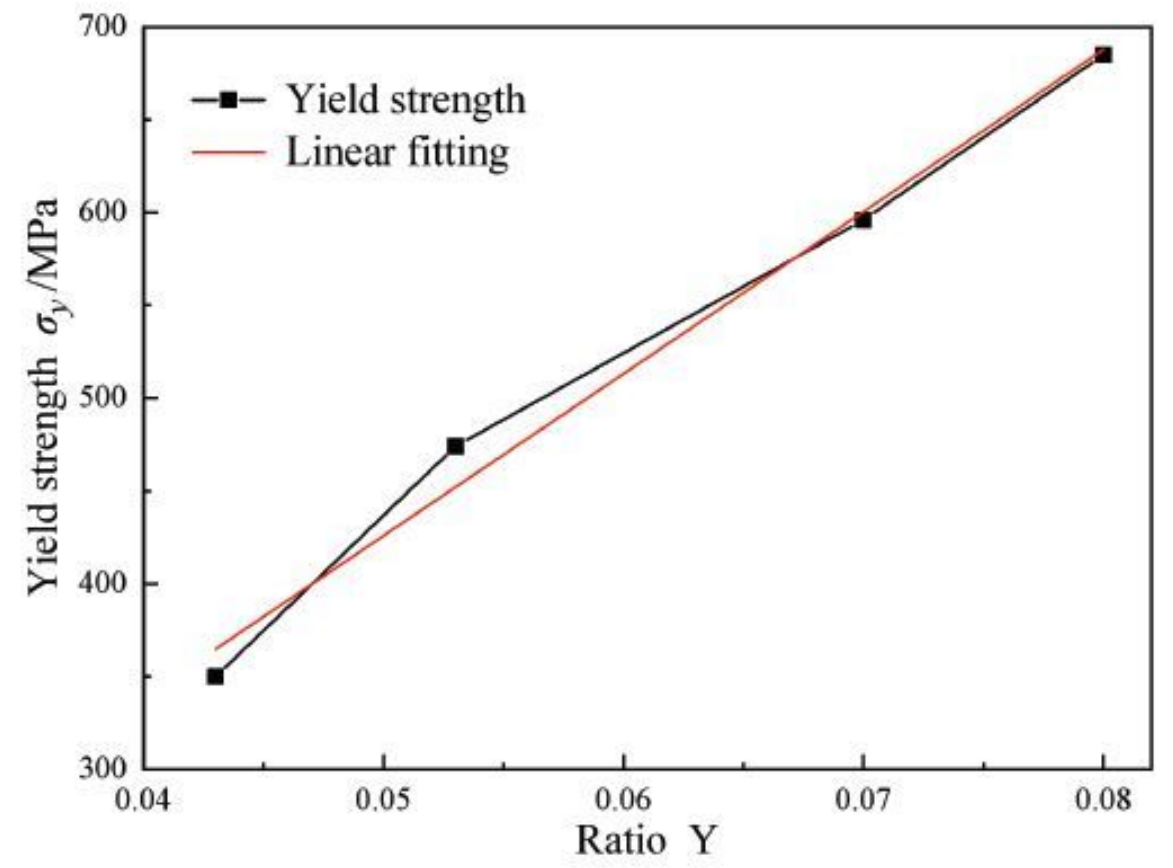

b

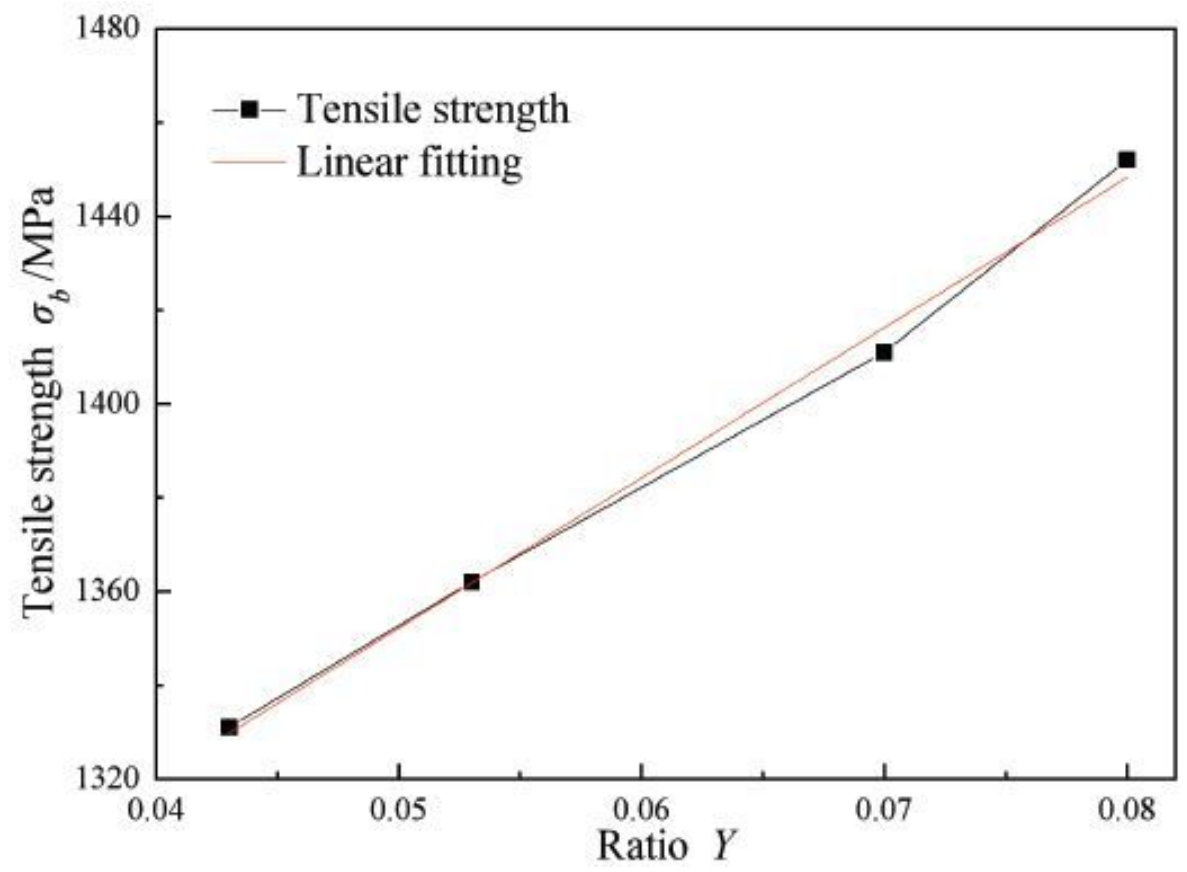

Figure 11

a Fitting curve of yield strength and ratio $Y ; b$ fitting curve of tensile strength and ratio $Y$ 


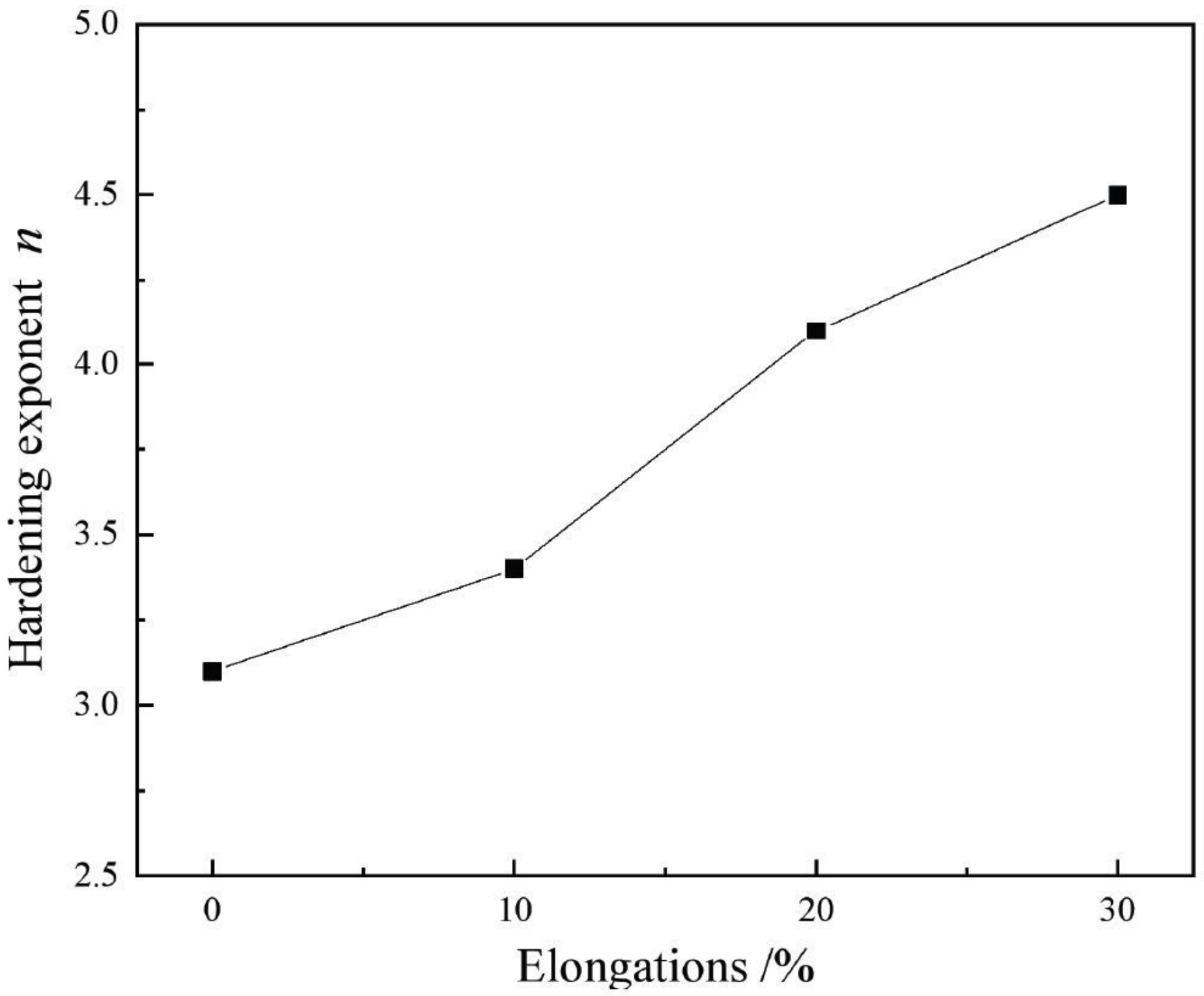

Figure 12

Change law of hardening exponent under different elongations 


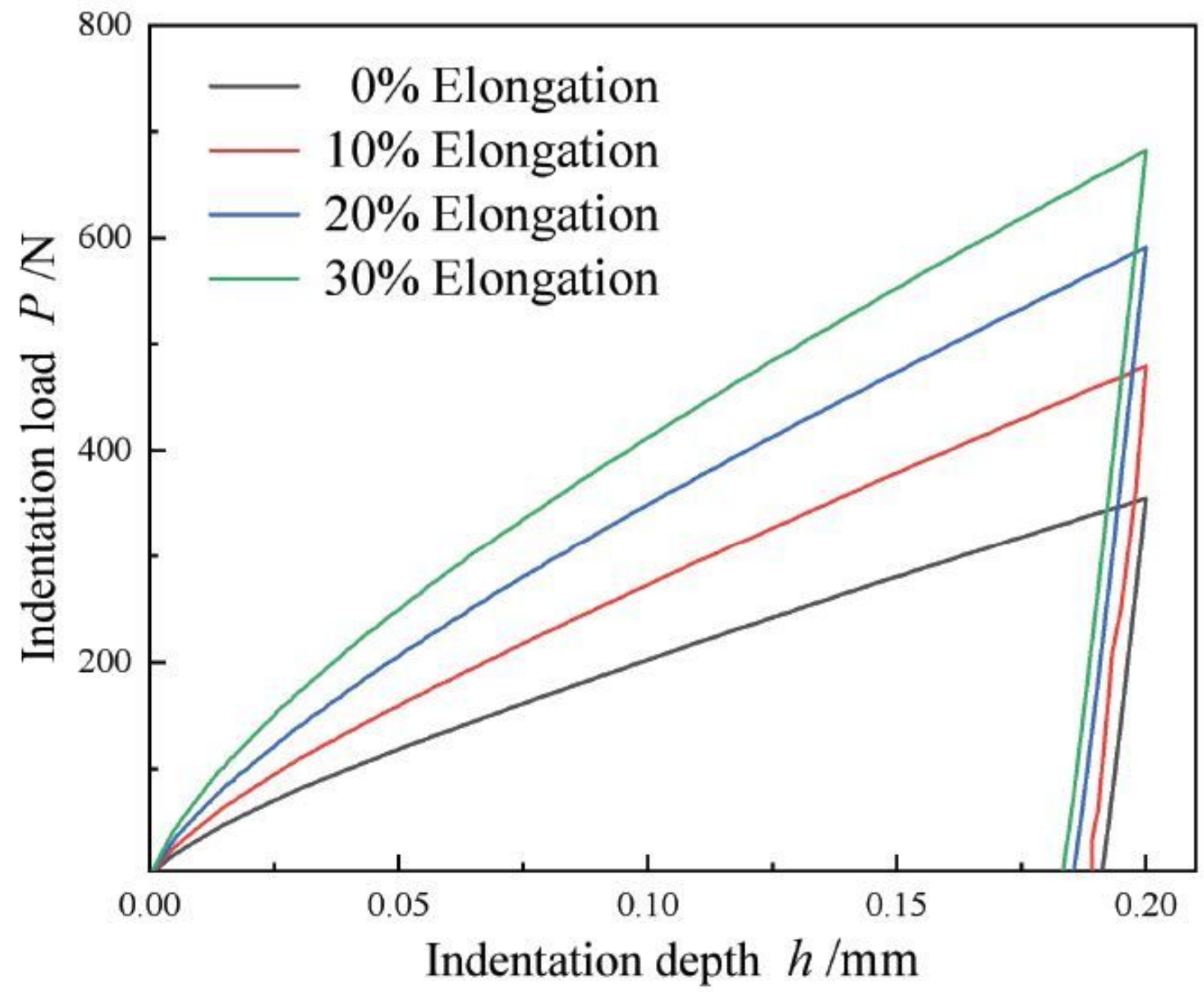

Figure 13

The load-depth curve obtained by finite element reversion under different elongations 
a

S, Mises
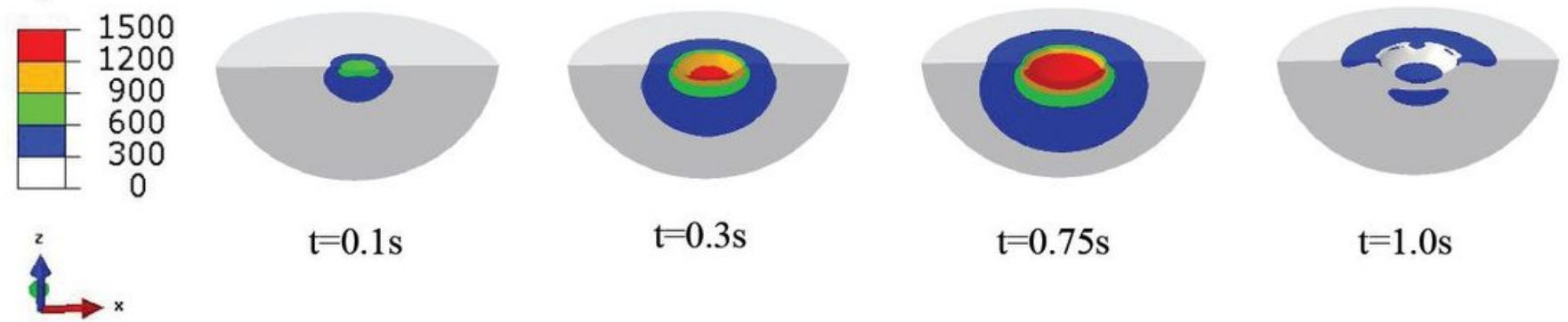

$\mathrm{t}=0.1 \mathrm{~s}$

$\mathrm{t}=0.3 \mathrm{~s}$

$\mathrm{t}=0.75 \mathrm{~s}$

$\mathrm{t}=1.0 \mathrm{~s}$

b
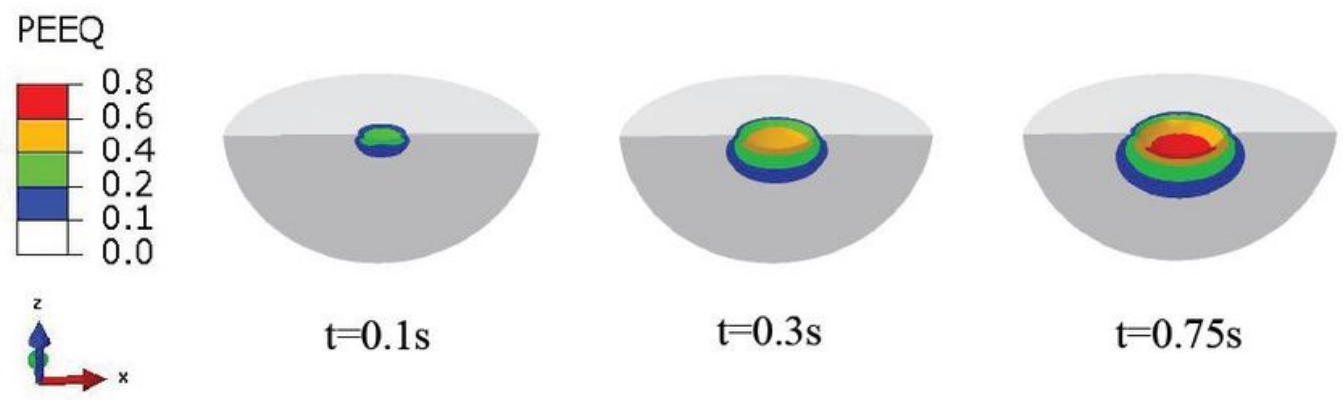

$\mathrm{t}=0.1 \mathrm{~s}$

$\mathrm{t}=0.3 \mathrm{~s}$

$\mathrm{t}=0.75 \mathrm{~s}$

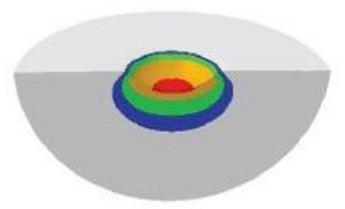

$\mathrm{t}=1.0 \mathrm{~s}$

Figure 14

Mises stress of indentation process under $10 \%$ elongation; $b$ equivalent plastic strain (PEEQ) of indentation process under $10 \%$ elongation 


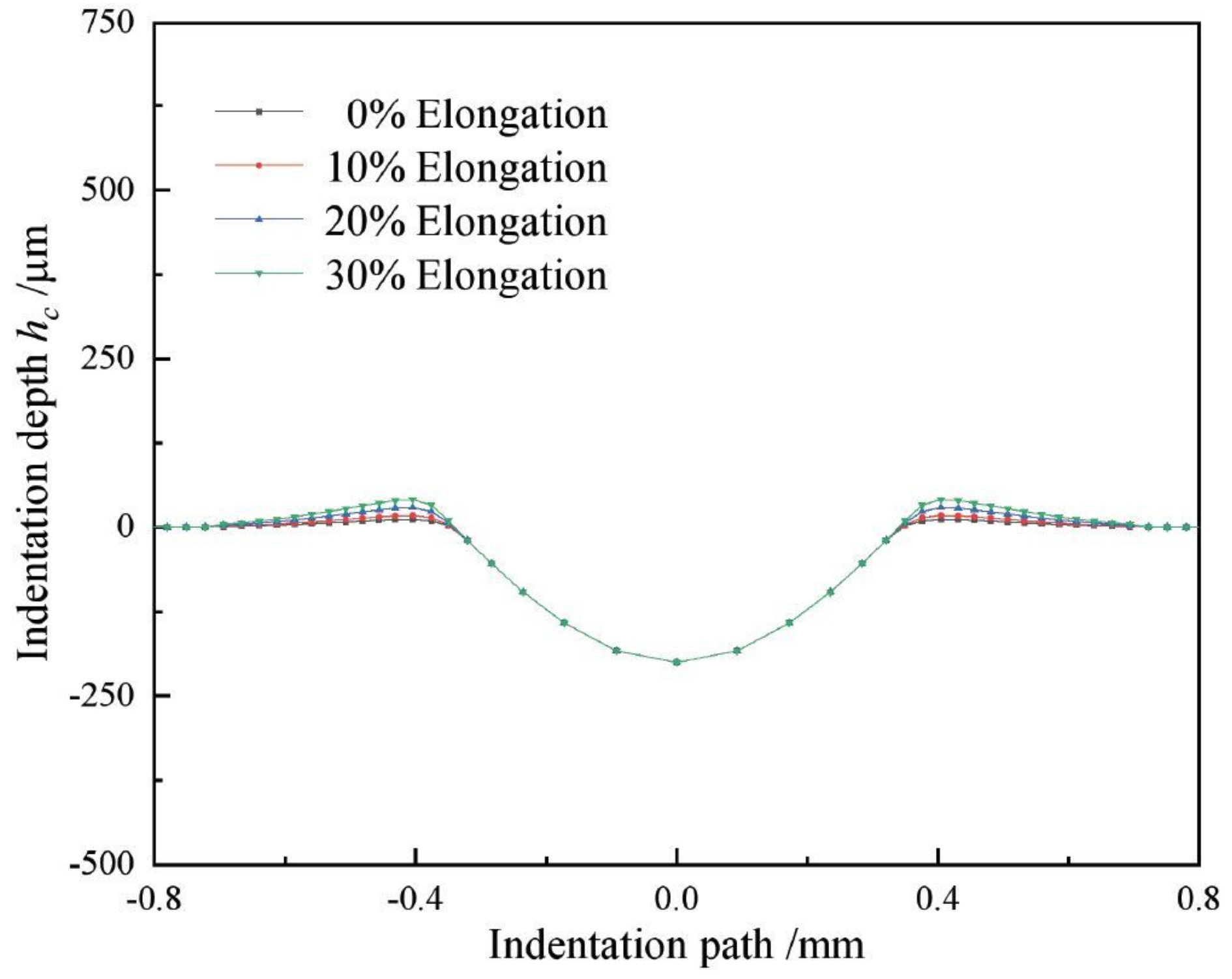

Figure 15

Comparison of maximum indentation morphology under different elongations 

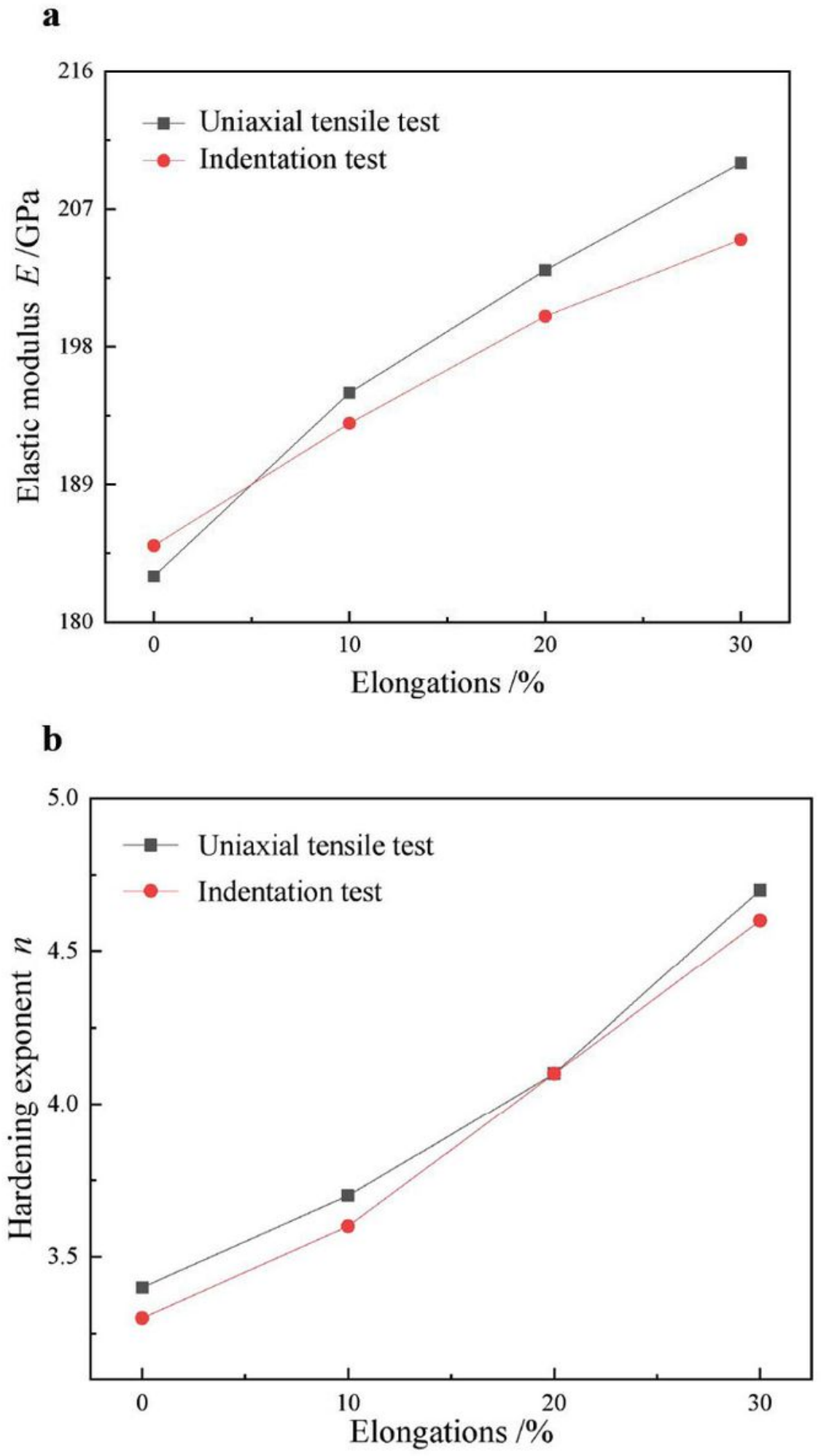

Figure 16

Comparison of mechanical parameters obtained by indentation test and tensile test under different elongations: a Elastic modulus; $b$ hardening exponent 


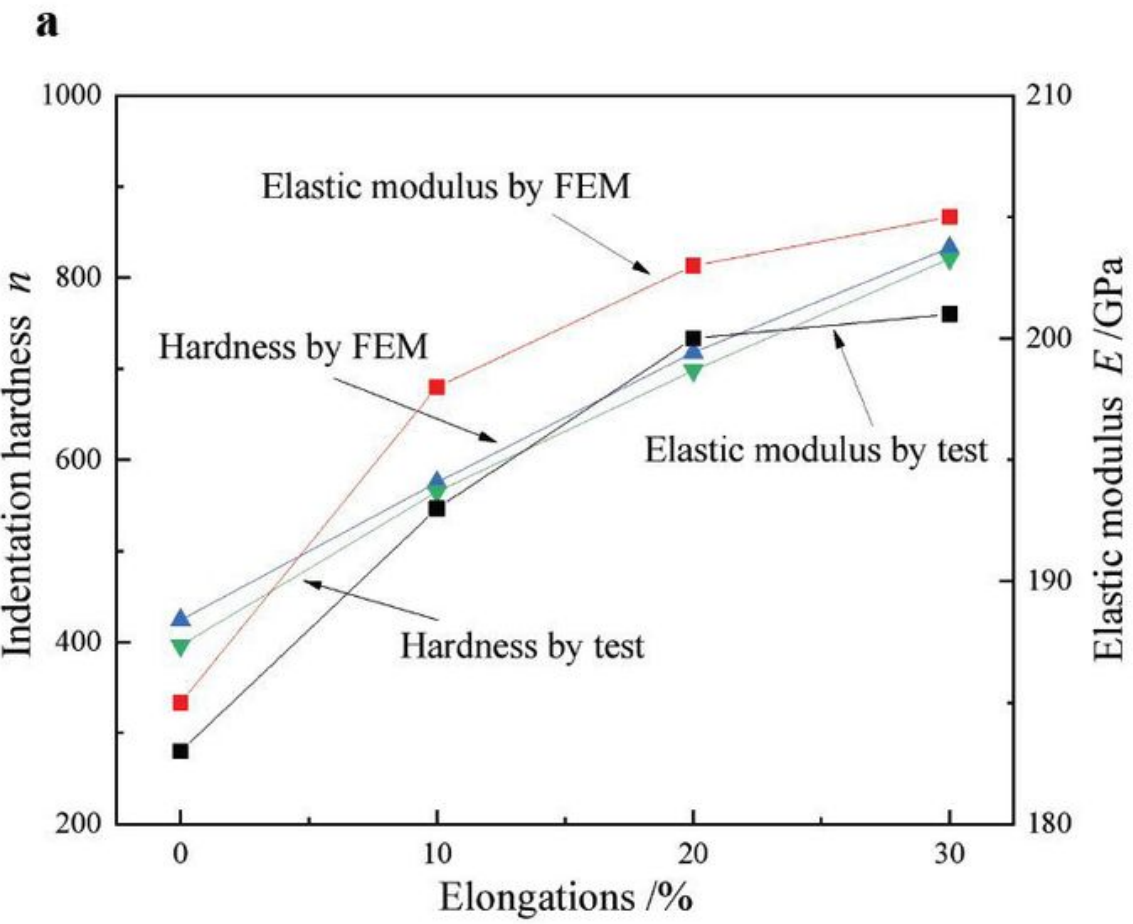

b

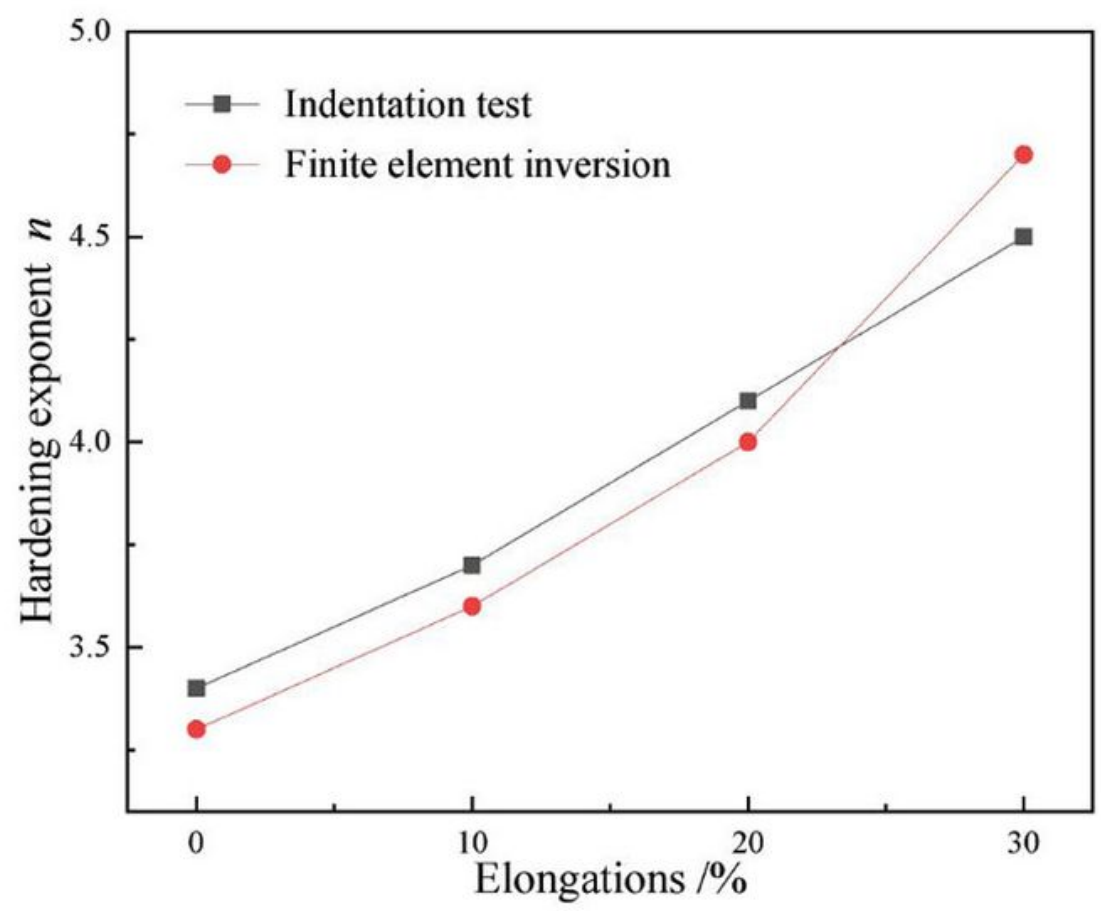

Figure 17

Comparison of mechanical parameters obtained by indentation test and finite element method with different elongations: a Elastic modulus and hardness; $b$ hardening exponent 